\title{
A Demonstration of the Application of Quantized Spatial Transforms in the Scaled and Optimized Separation of Scalar Potential Source Contributions for Use in Education, Research and Resource Exploration
}

\author{
Andrew M. McDermott ${ }^{1} \&$ Jeffrey R. Chiarenzelli ${ }^{2}$ \\ ${ }^{1}$ Independent research consultant, Potsdam, NY, USA \\ ${ }^{2}$ Department of Geology, St Lawrence University, Canton, NY, USA \\ Correspondence: Andrew M. McDermott, P. O. Box 281, Potsdam, NY 13676, USA. Tel: 1-315-566-1450. \\ E-mail: selkienadiasdad@care2.com
}

\author{
Received: January 2, 2014 Accepted: January 16, 2014 Online Published: April 2, 2014 \\ doi:10.5539/esr.v3n2p1 URL: http://dx.doi.org/10.5539/esr.v3n2p1
}

\begin{abstract}
An approach to the inverse Fast Fourier Transform (IFFT) isolation and identification of geological source contributions to surface gravitational and magnetic attractions is demonstrated. The techniques were developed from considerations of the scaling and linearity of the continuous Fourier transform and the properties of the classical potential fields. The approach exploits the characteristics of the discrete vertical spectral components of the FFT and their equivalent IFFT representations. The results depend upon absolute and relative quantitative comparisons over scaled regions represented within the digitized transform of the grid-based surface interpolated from the original field measurements. They provide for quantified estimates of parameters related to equivalent source contributions to anomalies identified within the surface. The techniques can be optimized with respect to the goals and resources associated with a particular investigation. Anomalies within FFT/IFFT filtered spatial residuals from a transformed digital surface are defined in terms of localized reference levels over scaled central sub-regions of a surveyed area. Iterative methods lead to particular subsets of the discrete depth components viewed over scaled spatial regions which contribute to identifiable features. Such identification can yield information related to the physical properties of sources responsible for regional and localized anomalies. The depth, spatial extent, and density or magnetization associated with these contributions can be estimated directly from the scaled views. These methods can be applied with predictable accuracy over orders of magnitude in physical scale. The quantitative information derived from the techniques provides for a scaled reduction in the ambiguity associated with any subsequent interpretation.
\end{abstract}

Keywords: spectral separation, spatial and depth resolution, gravity and magnetic anomalies, FFT, digital analysis, density and magnetization

\section{Introduction}

The classical theory of the attractive potential and the mathematical properties of the continuous Fourier transform (CFT) were the foundations upon which sophisticated analytical tools related to the spectral characterization of subsurface sources were developed (Bhattacharrya, 1967). These tools provided for the estimation of values related to the depth, size, and density or magnetization of these sources (cf. Sharma, 1997). The quantitative limitations which affect standard spatial and spectral analysis of scalar potential source contributions to the surface attraction have inspired the design of alternative technologies, e.g. discrete wavelet analysis (Hornby et al., 1999) and methods based on finite element concepts (Mallik \& Sharma, 1997). Despite decades of such development "... precise information about density, depth position, and depth extent of the sources...cannot be obtained from the ... anomaly alone because of non-uniqueness and stability problems" (Beltrão \& Silva, 1993).

The analytical tools used in spectral and spatial geophysical processing are based in a tradition of integral and differential equations derived from classical potential theory. Field measured values are treated as elements contributing to a continuous surface. Parameters related to the sources responsible for these measurements must 
be estimated or generated through regional-residual separation, enhancement, modeling, and inversion methods. Field surveys are designed in terms of the source bodies of interest to a particular investigation. The samplings are performed at locations which provide an effective average coverage with separations that are a few percent of the survey area of interest (cf. Hinze, 1990 or Mishra \& Tiwari, 2011). The information related to smaller, presumably shallow, sources is treated as noise and generally removed or smoothed so as to "...not try to interpolate the data, but rather find an approximation by fitting the error envelope" (Rauth, 1998). Conventional separation and transformation techniques rely upon the definition of a residual anomaly of interest. "The definition of the residual anomaly is not very precise...is problem dependent .... The subjectivity of the residual determination process makes it potentially one of the major limitations of applying gravity and magnetic methods" (Hinze, 1990).

The theory of the discrete Fourier Transform (DFT) establishes a framework for investigating and quantifying the relationship between discrete surface measurements of the attraction due to the Earth's scalar potential fields and the physical characteristics of localized sources within a continuous subsurface distribution. Discrete measurements must be interpolated to a line or grid, 1 or 2 dimensional spatial arrays of mathematically resampled values, in order to apply the techniques of digital signal processing (DSP). Sampling theory (Shannon, 1949) provides for an objective and quantified limit on the spectral and spatial resolution which can be realized through DFT methods applied to a digitized signal representing such a field survey. This limit imposes a priori constraints on the original survey design. A localized oscillatory phenomenon, 'aliasing', may distort the filtered information and thereby limit the spatial resolution inherent to the analysis. A relationship exists between the finite extent of the survey region and contamination by large-scale, oscillatory edge effects. Inadequate or irregular survey design or improperly resampled digital grids representing the measurements present obstacles to subsequent analysis and interpretation.

The introduction of the fast Fourier transform (FFT) algorithm (Cooley \& Tukey, 1965) made it possible to efficiently and accurately exploit the spectral characteristics of the digital signals interpolated from the sampled surface attractions. The implementations of FFT algorithms are dependent upon the mathematical properties of the discrete and infinite Fourier transform. They are subject to the constraints imposed by the transformation of a finite and non-periodic signal. One consequence of the use of finite and discrete sampling methods is the necessary quantization of the vertical spectrum, i.e. the discrete nature of the depth-based information. There is to date only a single discussion available related to the characterization of the discrete vertical spectral information $\left(\mathrm{k}_{\mathrm{z}}\right.$ ), or equivalently the discrete inverse FFT (IFFT) depth components (McDermott \& Chiarenzelli, 2013). This characterization reveals the significance of this classical spectral quantization in the separation of source contributions to measurements related to surface gravity or magnetization. Conventional perspectives consider that “... Separation filtering becomes very difficult when there is considerable overlap in the spectra of individual depth ensembles...In practice, it is usually impossible to achieve complete separation because the problem is non-linear and spectra have too much overlap" (Cowan \& Cooper, 2005). The discrete vertical elements provide for a minimum uncertainty set of basis components for separation in the spectral, or wavenumber, domain. Spectral overlap occurs only within, not between, individual vertical wavenumber components. Each of these is associated with a unique depth which can be considered to represent the mean value over some range. The inverse transforms of the vertical spectral elements constitute a set of irresolvable minimum ambiguity components for depth separation in the spatial domain.

The quantization revealed by spectral characterization makes it possible to replace conventional problem-dependent residual analysis with a generalized DSP- based separation methodology. It provides for a basis set of arrays whose elements represent the two dimensional spectral components $\left(\mathrm{k}_{\mathrm{x}}, \mathrm{k}_{\mathrm{y}}\right)$ as a function of the vertical components $\mathrm{k}_{\mathrm{z}}$ for the digital surface interpolated from the original measurements. These are subject to the basic rules of linear algebra. Each array in the inverse-transformed spatial basis corresponds to a unique depth. The linearity of the Fourier transformation guarantees that the application of a sharply defined FFT filter in the z-direction is equivalent to a simple superposition of a contiguous subset of the basis of spatial arrays. The individual elements within each of these arrays represent the point-by-point source contributions associated with that depth within the original interpolated digital surface.

The purpose of this paper is to demonstrate a quantified and objectively scaled approach to the implementation of the FFT as an anomaly separation and enhancement tool. The methods take advantage of the equivalence of the spectral and spatial information associated with the transforms in order to work exclusively with the spatial components. They are based in traditional techniques adapted in innovative ways (McDermott, 2006). The approach is founded upon the fundamental mathematical properties of the Fourier transform and the physical properties of the scalar potential. It respects the scaling principles which characterize the normal components of 
the attractive forces of the earth's surface gravity and magnetization. The methods exploit the characteristics of the discrete vertical spectral and spatial information of the transformed digital surfaces interpolated from field measurements (McDermott \& Chiarenzelli, 2013). This discussion is concerned with the practical application of techniques based upon the inherent scaling of the discrete vertical components to the measurements from a particular representative field survey.

\section{Methods}

\subsection{Geological Background and Motivation}

The Adirondack Lowlands are located in the northwestern part of the Adirondack Region and serve to connect the Precambrian rocks exposed there with the Canadian Shield (see McLelland et al., 2010 for an extensive introduction to the region). The Lowlands have been differentiated from the Adirondack Highlands on the basis of a larger portion of meta-sedimentary rocks, lower metamorphic grade, and lesser topographic relief. The boundary between the two regions, the Carthage-Colton Shear Zone, has a long complex history. It most recently served as an extensional, orogenic collapse structure (Selleck et al., 2005; Wiener, 1983). In contrast to the Highlands, the Lowlands were last deformed and metamorphosed during the Shawinigan Orogeny (1190-1150 million years ago; Heumann et al., 2006).

The Balmat-Edwards mining district is located within the Lowlands. The district has a long history of zinc production dating back almost a century (Knight, 2005). The meso-proterozoic sphalerite deposits, are highly deformed and metamorphosed to mid-upper amphibolite grade. They are believed to represent sedimentary exhalatives deposited on the floor of a shallow sea (Whelan et al., 1984). They are found in the marble-evaporite sequence known as the Upper Marble and occur within the overturned Sylvia Lake Syncline (DeLorraine \& Sangster, 1997). While ore bodies concordant with lithologic units have been actively mined, considerable amounts of ore are also found along ductile faults which connect many of the stratiform ore bodies, suggesting remobilization of the sulfide ore (DeLorraine, 2009). Mining has occurred in many spatially separated ore bodies at depths from near surface to $1200 \mathrm{~m}$ below the surface.

Exploration and mining within the Sylvia Lake Syncline has led to the recognition of 16 units within the Upper Marble (DeLorraine \& Sangster, 1997). Tens of thousands of diamond drill cores tightly constrain the overall structure and stratigraphy of the area, which is the best known in the Adirondack Region. Analysis of a subset of set of regional gravity datum (Revetta \& McDermott, 2003) centered on the Sylvia Lake Syncline at Balmat, New York was selected. The included measurements extended 1 degree in latitude and longitude. A study initiated in 2002 was undertaken to determine if the techniques to be described could:

- Accurately represent the stratigraphy known from previous investigations;

- Accurately represent the overall structure of the area; and

- Accurately locate any rocks of high density (undiscovered ore deposits composed primarily of sphalerite and associated sulfide minerals).

\subsection{Data Reduction and Grid Assignment}

The corrections applied to the field measurements were chosen only to compensate for instrumental or procedural conditions or to satisfy the prerequisites of DFT theory. Subjective adjustments based upon assumed or inferred geology were not performed, e.g., isostatic residuals and decompensative anomalies for gravity studies. The regional or theoretical reference field (1967 International Gravity Formula) was removed to provide for a reasonable, full region reference level for the potential. Neither smoothing nor direct correction of high wavenumber components was performed. The focus of the efforts included recognition and quantification of the error contributions associated with measurement and calculation. Particular attention was given to the errors and distortions traditionally associated with FFT-based spectral methods. The oscillatory distortion introduced by FFT vertical/depth separation was systematically studied in an effort to regulate or limit its influence. Scaled extension of the reference region used for filtering with respect to a primary region of interest was employed. The reliability of higher order resampled interpolations was verified. Resampling was employed in order to increase the effective spatial resolution within the surface. It also served to reduce the influence of aliasing in the FFT procedures through the introduction of additional high wavenumber length scales. The original effective sample spacing of $1 \%(.01$ degrees, $\sim 1 \mathrm{~km})$ was decreased to $.1 \%$ and $.01 \%$ over the full 1 degree region used as a reference for filtering and for comparisons. The results in this discussion will be limited to regional and residual surfaces at the $.01 \%$ grid resolution.

A method was developed which facilitated the direct visual and mathematical comparison of interpolated reference surfaces and filtered residuals over a range of scaled views. This involved the use of a single contour 
and gradient scheme which can be assigned in two ways to each resulting regional surface or extracted sub-region:

- Absolute: scaled to fit the full range of values represented within the binary array which contains the values the array of interest.

- Relative/proportional: scaled to the absolute range of some other more depth-inclusive residual or unfiltered array extracted from the original full region interpolation.

Fifteen (15) contour intervals were employed within each half-range of the data. These were first shifted by a subtraction to the mean within each gridded surface. The preferred gradients employ a scaled color range, blue-grey-white (negative) and white-yellow-red (positive).

The FFT has been applied exclusively in filtering procedures using sharp cut-off limits. Each spatial residual (IFFT) represents the inverse transform over a depth interval associated with a particular set of discrete vertical spectral wavenumbers, i.e. inverse length components. The principle of superposition makes it possible to define a set of equivalent spatial sources over particular sub-regions which can, for convenience, be considered as centered at some mean depth. These are restricted to scaled central regions containing source contributions as represented in the original resampled field measurements. The approach amounts to an iterative and scaled decomposition over depth of the original interpolated surface at every point in the grid.

A short appendix has been included with a listing of representative command lines used to effect portions of the analysis as presented here. These have been implemented with the Generic Mapping Tools ('GMT', available at URL http://gmt.soest.hawaii.edu). The results could be duplicated using any equivalent or comparable set of software tools and resources. The use of command line tools provides for efficiency, control, and flexibility. The reduced cost and complexity of an approach which has been based upon the automation of such procedures through simple configurable scripts could benefit a broad range of academic and professional programs (cf. McDermott and Chiarenzelli, 2013 Supplementary material, available upon request).

\section{Results and Discussion}

\subsection{Separations at Depth}

"The value of the methods is that these observed variations...must relate to a greater or lesser extent to what we loosely term the 'geology' of the subsurface." (Paterson \& Reeves, 1985)

Figure 1a indicates the locations used for an irregular survey of a 1 degree region in upstate New York centered on the Balmat zinc mine. These were acquired with an effective average spacing of $1 \%$, or .01 degrees $(\sim 1 \mathrm{~km})$. Figure $1 \mathrm{~b}$ is the interpolated digital surface constructed from these measurements and resampled to $.01 \%$, or .0001 degree spacing. A centrally located .12 degree region containing the mine, which is of primary interest, has been indicated in the figure.

The dominant low wavenumber components represented within Figure $1 \mathrm{~b}$ have spatial transforms which can be correlated directly with the published results from a long range seismic study. Nine region-wide seismic reflective layers, and interpretations of their significance, have been reported by Hughes and Leugert (1992). Eight of these lie between a depth of $3000 \mathrm{~m}$ and the depth associated with the lowest wavenumber contained in the FFT of the digital surface represented by Figure 1b. The information in Figure $1 \mathrm{~b}$ corresponds to a maximum accessible depth of approximately $114000 \mathrm{~m}$. The reported seismic layers will be denoted as HL2 through HL9 in order of ascending depth. The Tahawus Complex, HL5, lies near or beyond the eastern limit of our reference region and has not been given any consideration to date. There is no obvious, direct visible correlation available for HL3. The influence on the regional gravity from the other layers can be identified directly through visual comparisons of the appropriate residuals.

Figure 1c is the result of removing a third-order polynomial trend surface (Figure 1d) from the reference region in Figure 1b. The location of a central primary region of interest has also been indicated. Trial and error, or reference to a list of discrete levels for the surface, can be used to produce residuals which are effectively superpositions of individual ordered spatial components (IFFTs). The FFT filters are all applied using sharp depth cutoffs which will always lie between successive components. The discrete nature of the information guarantees that there is no mixing or contamination from undesired contributions over depth. These figures demonstrate the scaled use of visual characteristics as part of the analysis. Each set of residuals viewed over a particular region or sub-region (Figures 1c, 1d) can be prepared with the gradient and contours presented in the view for the interpolated surface over that same area (Figure 1b). This provides for both an absolute reference and a scaled relative measure for all the related surfaces. The contours and gradient characterizing Figure $1 \mathrm{~b}$ will be applied to all the full region (1 degree) views which follow. 
The lowest wavenumber components represent the deepest spatial components for the region. Figure $2 \mathrm{a}$ is the contribution to Figure $1 \mathrm{~b}$ from the two lowest vertical components located at $113864 \mathrm{~m}$, a strong N-S gradient, and $81529 \mathrm{~m}$, a less intense E-W crossing trend. Figure $2 \mathrm{~b}$ is the superposed combination of all remaining components. This includes those from the third greatest depth of $66289 \mathrm{~m}$ to those of the shallowest component representing a depth of approximately 12.9 meters. The removal of a third order trend from Figure $2 \mathrm{~b}$ reveals a regional anomaly (Figure 2c) visually and numerically equivalent to that of Figure 1c for the purposes of analysis. Superposition of the two lowest wavenumber terms with the trend removed from Figure $2 \mathrm{~b}$ results in the surface in Figure 2d. This surface approximates Figure 1d, the trend removed from the original regional interpolation. These provide a best estimate of the depth to the bottom of the full set of contributions represented by the original surface without its low wavenumber background. It also serves as a reasonable estimate for the source depths of the large scale contributions mixed by the polynomial trend which was generated to fit that background.

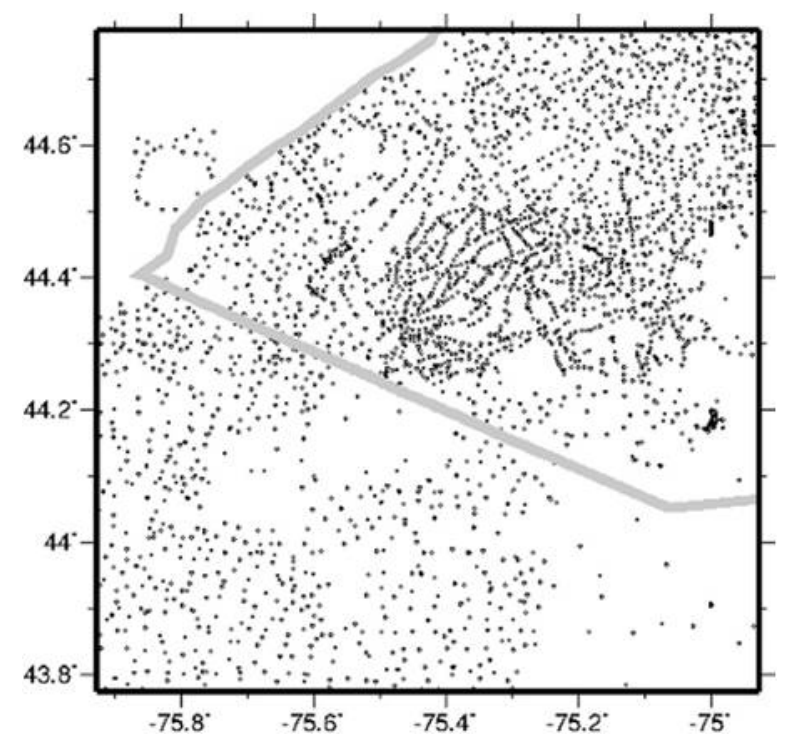

Figure 1a. Station locations for the field survey over a 1 degree region centered on a point within St Lawrence County, NY, USA. County boundary is indicated in grey

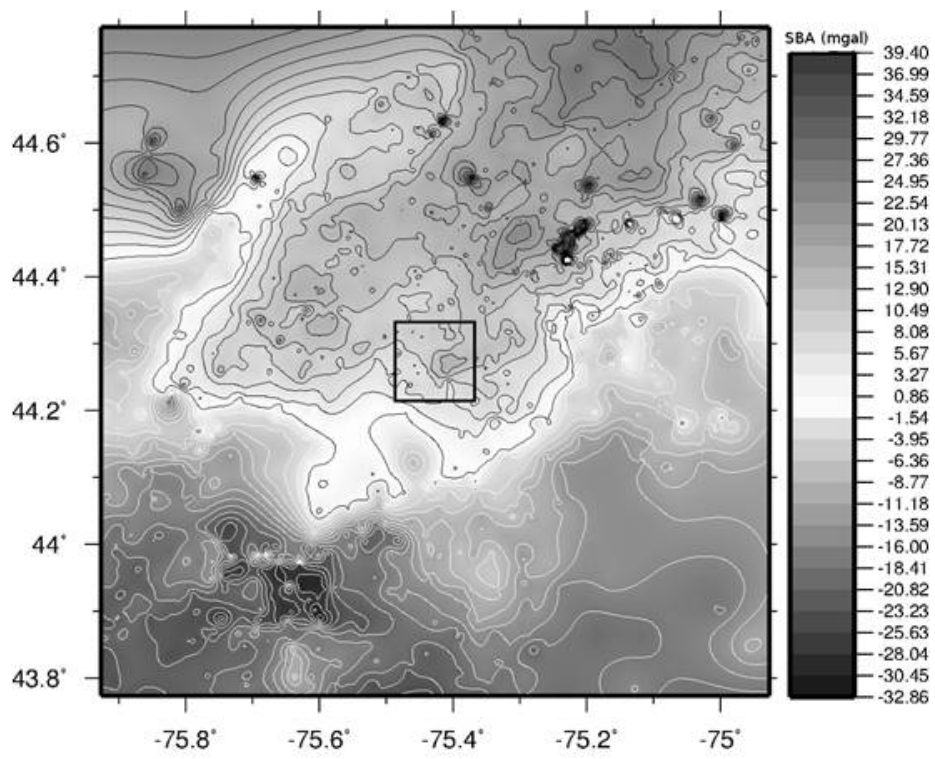

Figure 1b. Irregular field data interpolated to .0001 degree spacing over 1 degree reference region. Absolute visualscale (gradient and contours) applied. Central primary region of interest indicated 


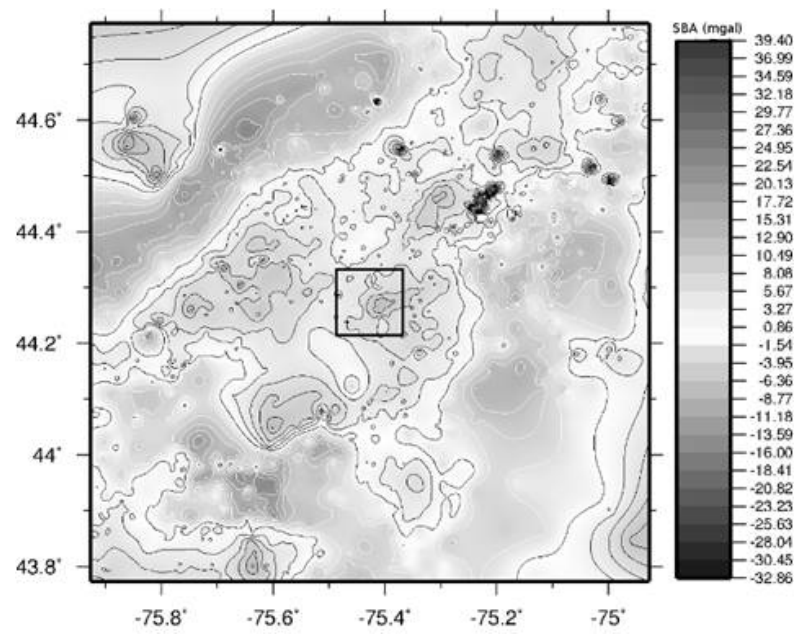

Figure 1c. Residual surface generated by removal of a third order polynomial trend from the surface in Figure 1b, assigned the visual scale of Figure 1b, .12 degree central primary region of interest indicated

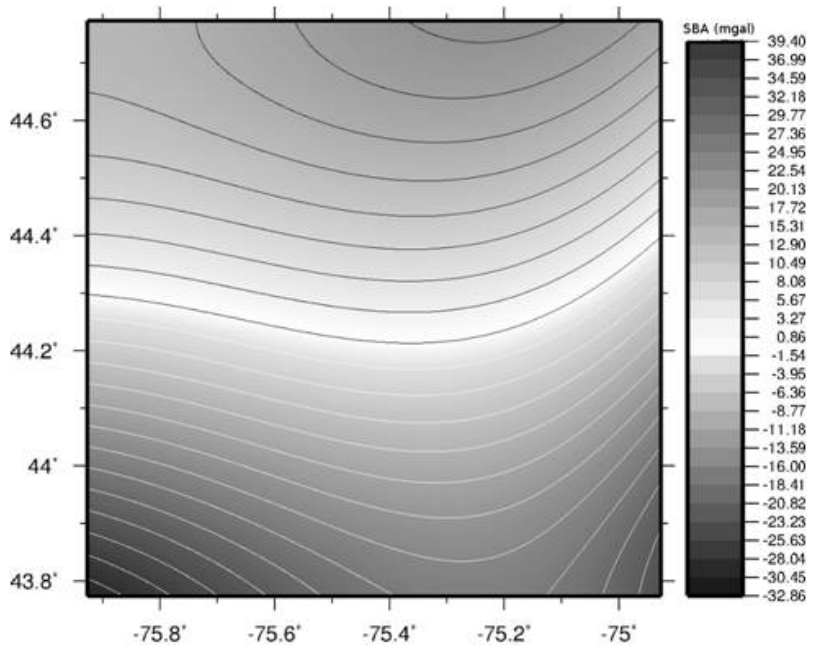

Figure 1d. Third order polynomial trend surface removed to produce Figure 1c, gradient and contours relative to Figure $1 \mathrm{~b}$, central primary region of interest indicated

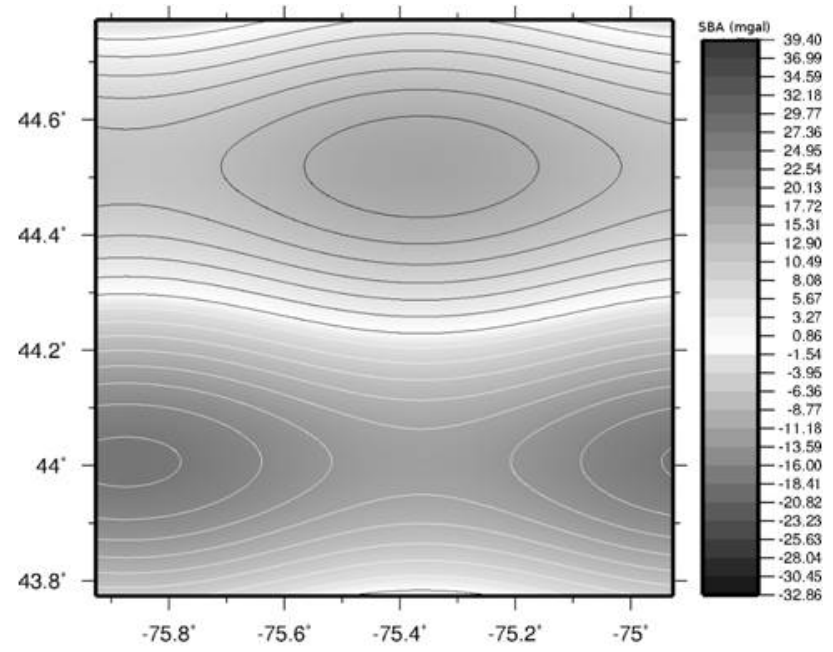

Figure 2a. Low pass IFFT, filtered over the 1 degree reference region of Figure $1 \mathrm{~b}$, filter bandwidth correlates to lowest 2 composite levels (depths below $68000 \mathrm{~m}$ ), no trend removed, assigned the visual scale of Figure $1 \mathrm{~b}$ 


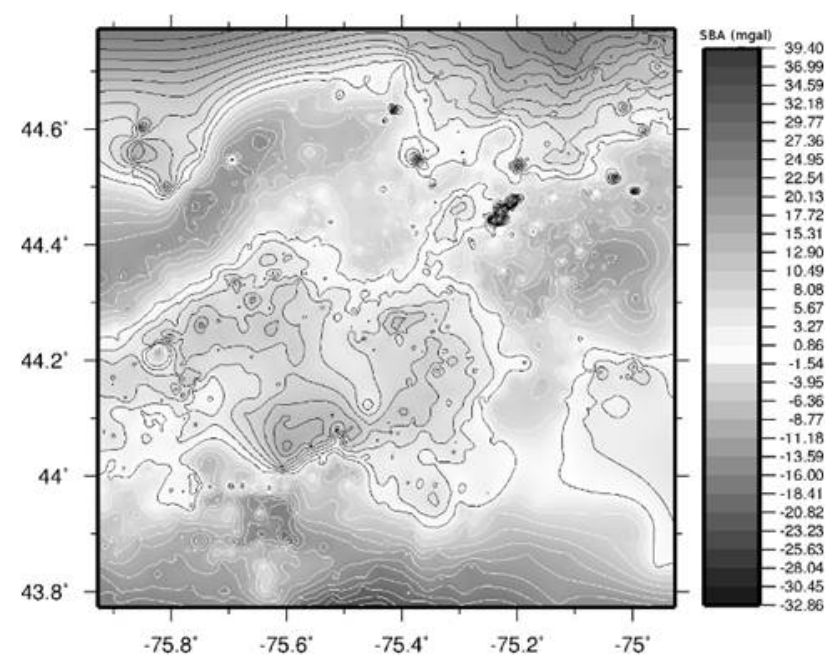

Figure 2b. 1 degree reference region residual, filtered from $68000 \mathrm{~m}$ to $\mathrm{z}=0 \mathrm{~m}$, visual scale of Figure $1 \mathrm{~b}$, no trend removed

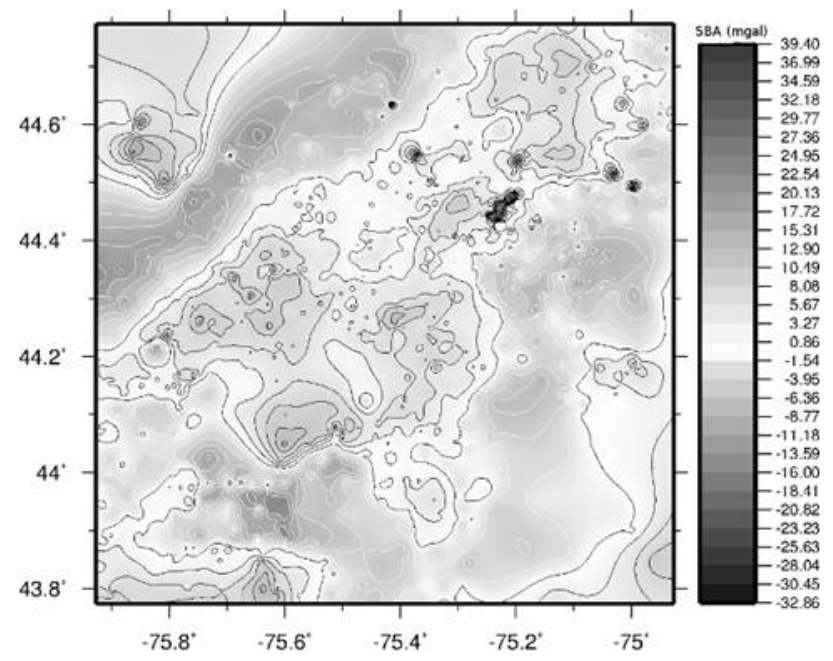

Figure $2 \mathrm{c}$. Figure $2 \mathrm{~b}$ after removal of a third order polynomial trend, assigned the visual scale of Figure $1 \mathrm{~b}$

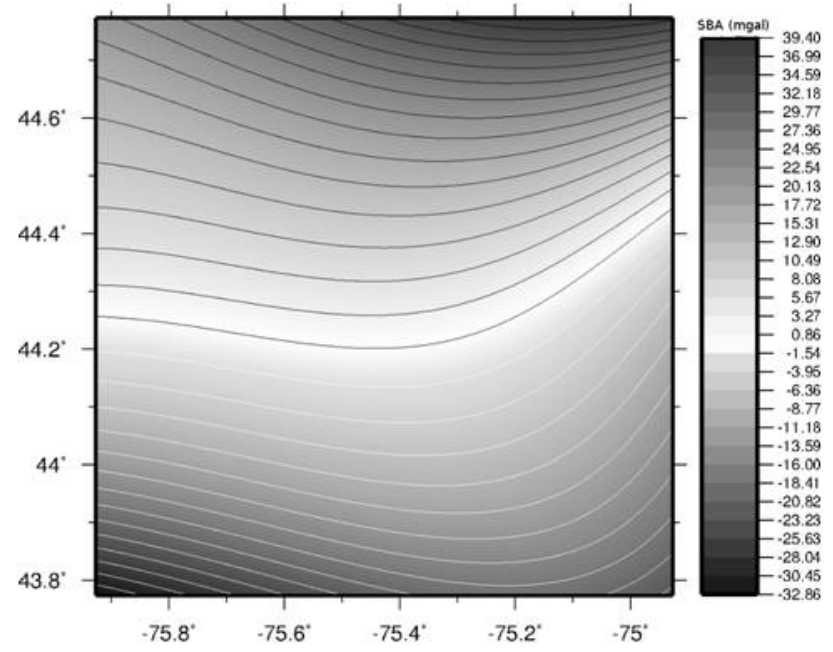

Figure 2d. Suggestive composite trend formed from surface of Figure 2a superposed with third order polynomial trend surface removed to produce Figure 2c, assigned the visual scale of Figure 1b 
The single component represented by the next level at $66289 \mathrm{~m}$ (Figure 3a) lies within a kilometer or so of the reported depth to an eclogitic lens which underlies most of the region (HL9). The next component, located at a depth at $56932 \mathrm{~m}$, is added to that of Figure 3a to produce Figure 3b. There is a transitional granulite-eclogitic layering (HL8) which the seismic studies place at or slightly above $60000 \mathrm{~m}$. The next component from the basis, associated with a depth of $46678 \mathrm{~m}$, has been added in Figure 3c. This includes the first influence of the transition through the Moho (HL7 at $\sim 45000 \mathrm{~m}$ ). Figure 3c displays some small shifting in the evolution of the contours from the previous figure. The final figure of this series (Figure 3d) reveals the full outline and dominant contours of Figure 2b. The next five successive components $(40765 \mathrm{~m}-33145 \mathrm{~m})$ have been included in this superposition. The upper limit of the depth filter in this image is just below $30000 \mathrm{~m}$, the depth reported for another reflective layer (HL6).

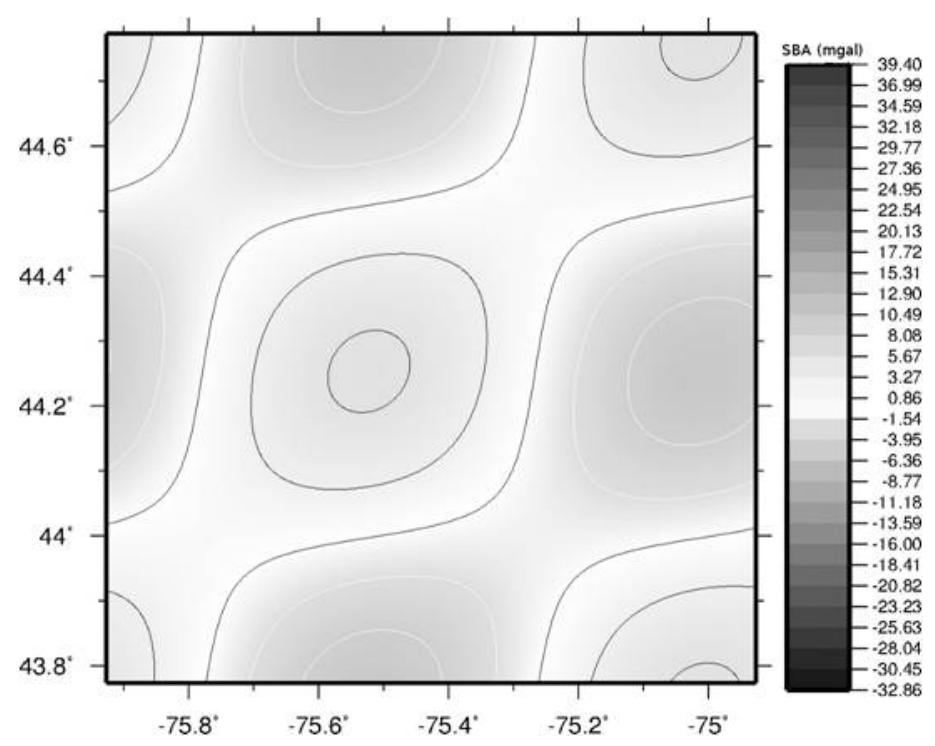

Figure 3a. Surface representing the third vertical spatial component at $66289 \mathrm{~m}$ corresponding to the eclogitic lens of HL9 ( $66000 \mathrm{~m})$ from the text, visually scaled to Figure 1b

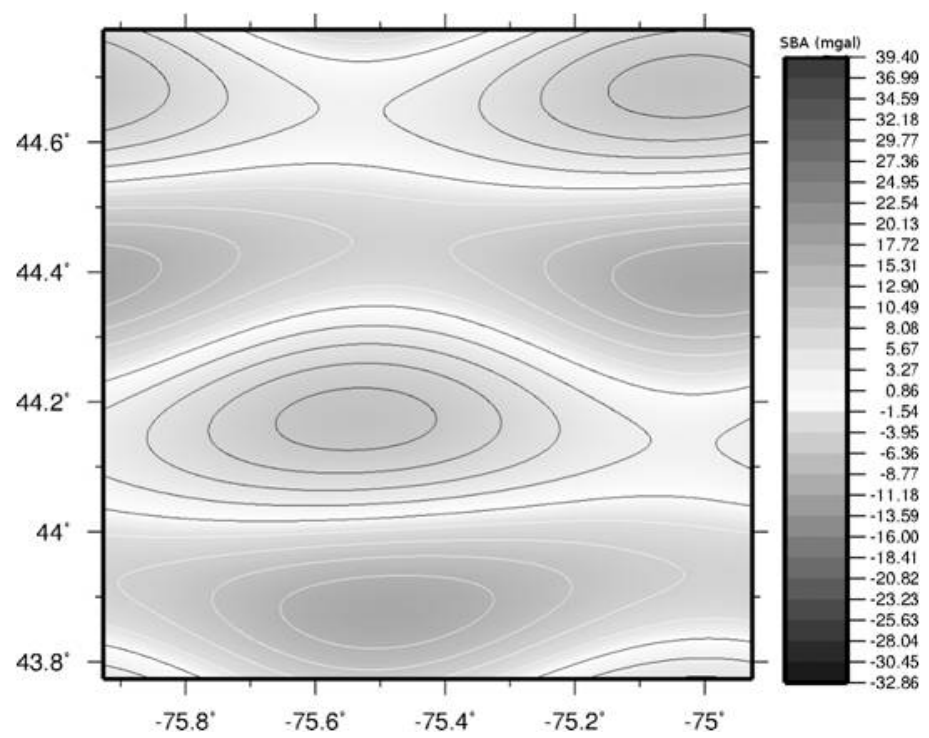

Figure 3b. Surface formed from the superposition of the fourth vertical component at $56932 \mathrm{~m}$ representing the granulite-ecologitic layer of HL8 ( $60000 \mathrm{~m})$ with the third component (Figure $3 \mathrm{a})$, visually scaled to Figure $1 \mathrm{~b}$ 


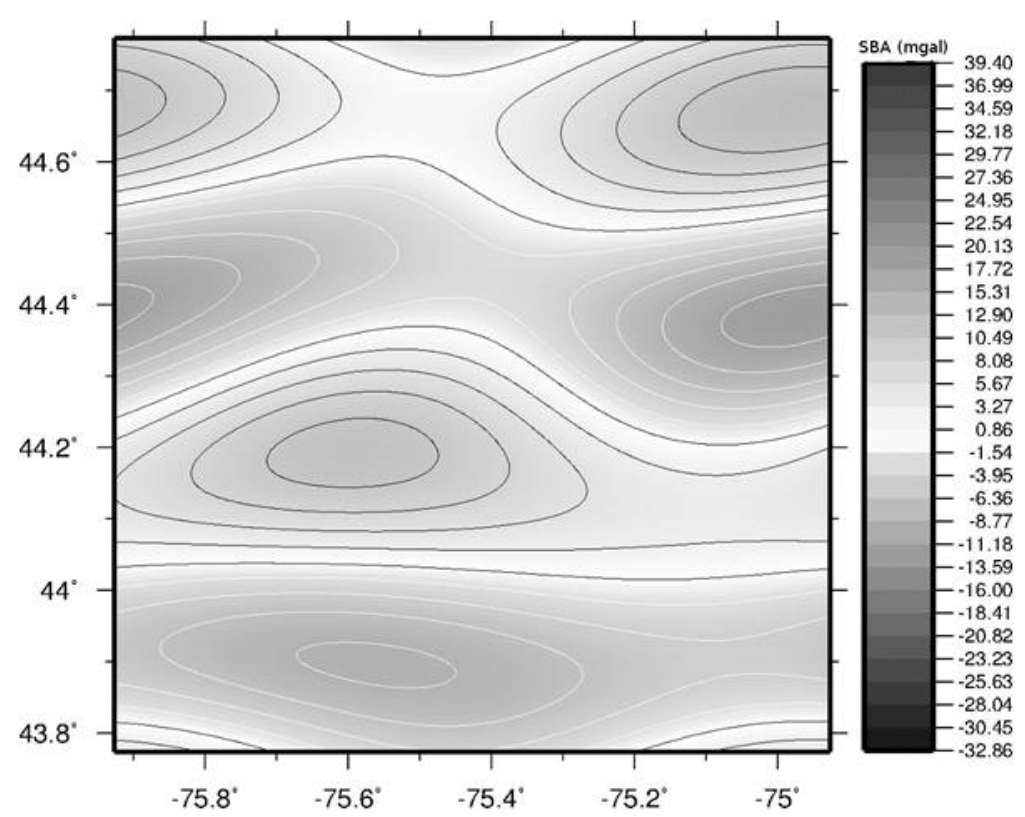

Figure $3 \mathrm{c}$. The surface of Figure $3 \mathrm{~b}$ after superposition with the 5 th vertical component $(46678 \mathrm{~m})$ at the crustal transition (Moho) of HL7 ( 47000 m), visually scaled to Figure 1b

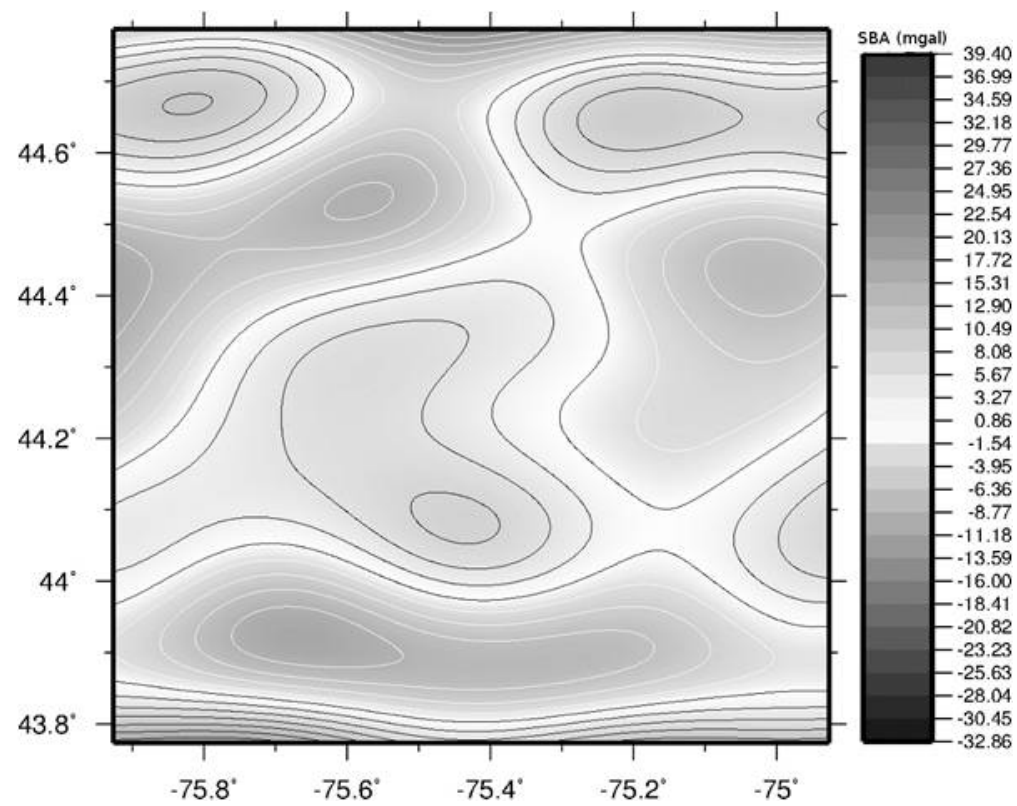

Figure 3d. Superposition of surface of Figure 3c with the next 5 vertical components which lie between $46678 \mathrm{~m}$ and $30000 \mathrm{~m}$ (depth of HL6), scaled to Figure 1b

Above $30000 \mathrm{~m}$ there is a distinct reduction in size and change in the ordering among the visible anomalies. The average spacing between individual depth components over this interval decreases from more than $500 \mathrm{~m}$ at a depth of $28466 \mathrm{~m}$ to $50 \mathrm{~m}$ at depths near $10000 \mathrm{~m}$. The 71 distinct components representing source contributions between $30000 \mathrm{~m}$ and $10000 \mathrm{~m}$ (Figure 4a) can be filtered with bandwidths that decrease from a few thousand meters at $30 \mathrm{~km}$ to hundreds of meters or less at $10 \mathrm{~km}$ depths in order to reveal stable intermediate anomalies. These represent information concerning an evolution which is consistent with the features visible in Figure 4a. A reflective layer has been reported at the upper depth for this series at $10000 \mathrm{~m}$ (HL4). The average size and the visible order of the visible structures shift as the filters are restricted above this depth. This can be seen in a comparison of Figures $4 a$ and $4 b$.

Above $10000 \mathrm{~m}$ we restrict the view over the full region to a set of three filters. These correspond to depths from 
10000-5000 $\mathrm{m}$ in Figure 4b, 5000-3000 $\mathrm{m}$ in Figure 4c, and 3000m to $\mathrm{z}=0$ in Figure 4d. Separations between individual depth components decrease in a regular manner to an average of $4 \mathrm{~m}$ near depths of $3 \mathrm{~km}$. The separations continue to decrease, e.g., from $1 \mathrm{~m}$ at a depth of $1 \mathrm{~km}$ to $.00001 \mathrm{~m}$ at the limiting depth determined by the grid employed $(12.95 \mathrm{~m})$. Figure $4 \mathrm{~d}$ is the result of filtering the anomalies above $3000 \mathrm{~m}$, the depth of the base of the Carthage-Colton Shear Zone, or CCSZ (HL2 at $3000 \mathrm{~m}$ ). The scale of size and ordering of the features have again shifted at the depths associated with a known reflective layer. It is necessary to reduce the view to a smaller central region, as indicated in Figures $1 \mathrm{~b}$ and $1 \mathrm{c}$, in order to consider the visible anomalies at an appropriate scale. This restriction also serves to exclude the increasing edge effects which result from the consideration of smaller depth intervals as the mean depth and component separations decrease.

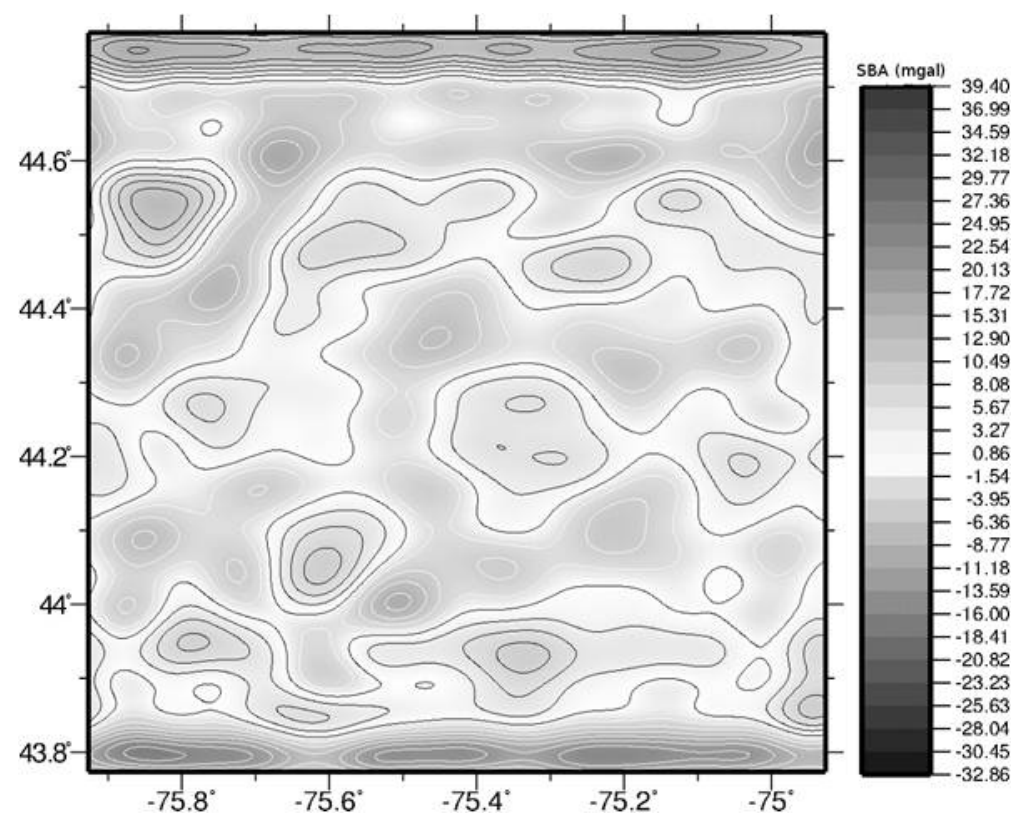

Figure 4a. Superposition of all vertical components above HL6 ( 30000 m) and below HL4 ( 10000 m) over 1 degree region, visually scaled to Figure $1 \mathrm{~b}$

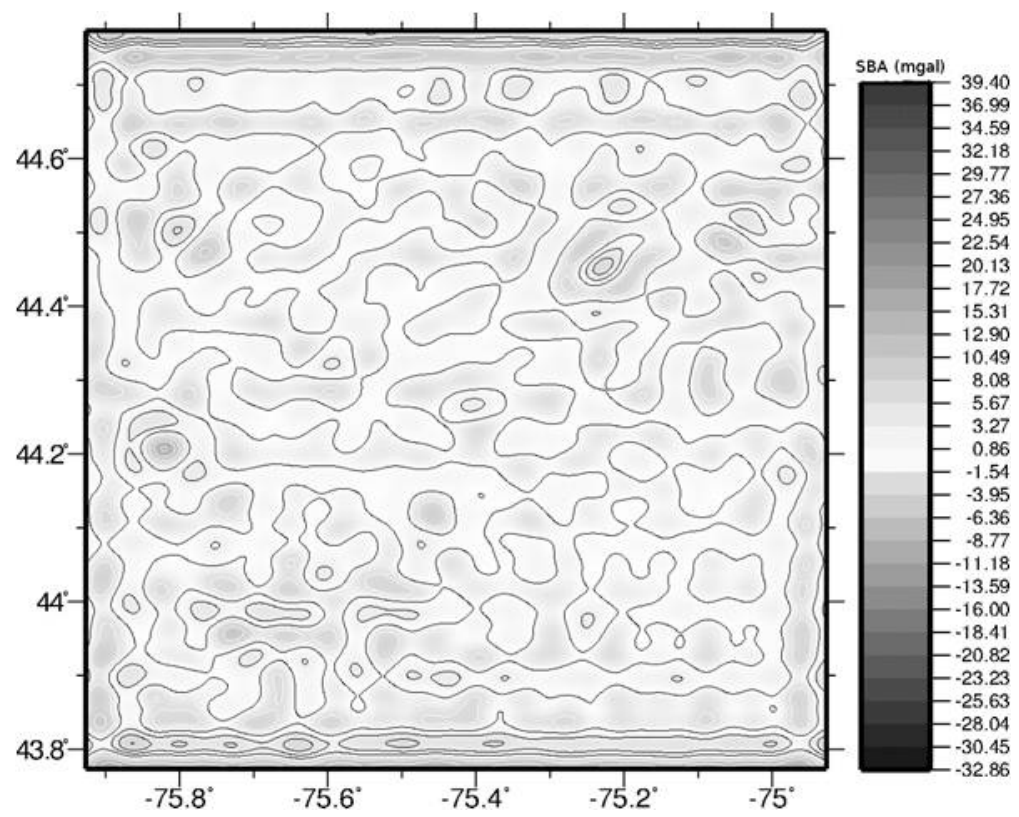

Figure 4b. Superposition of all vertical components above HL4 ( 10000 m) and below $5000 \mathrm{~m}$ over 1 degree region, visually scaled to Figure $1 \mathrm{~b}$ 


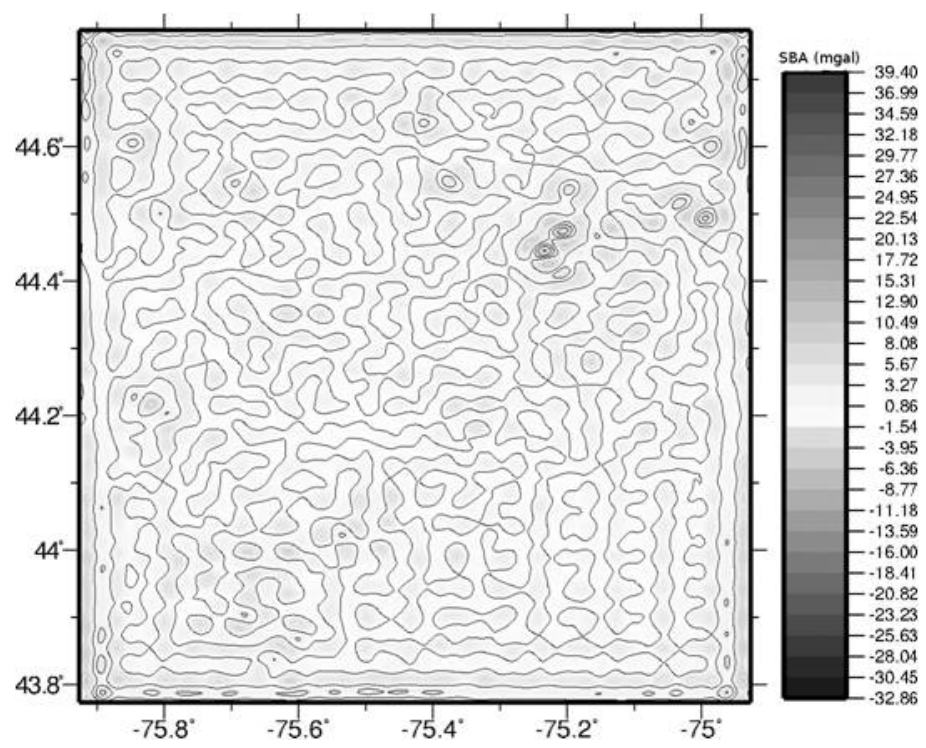

Figure 4c. Superposition of all vertical components above $5000 \mathrm{~m}$ and below the base of the Carthage-Colton Shear Zone (HL2 3000 m) over 1 degree region, visually scaled to Figure $1 \mathrm{~b}$

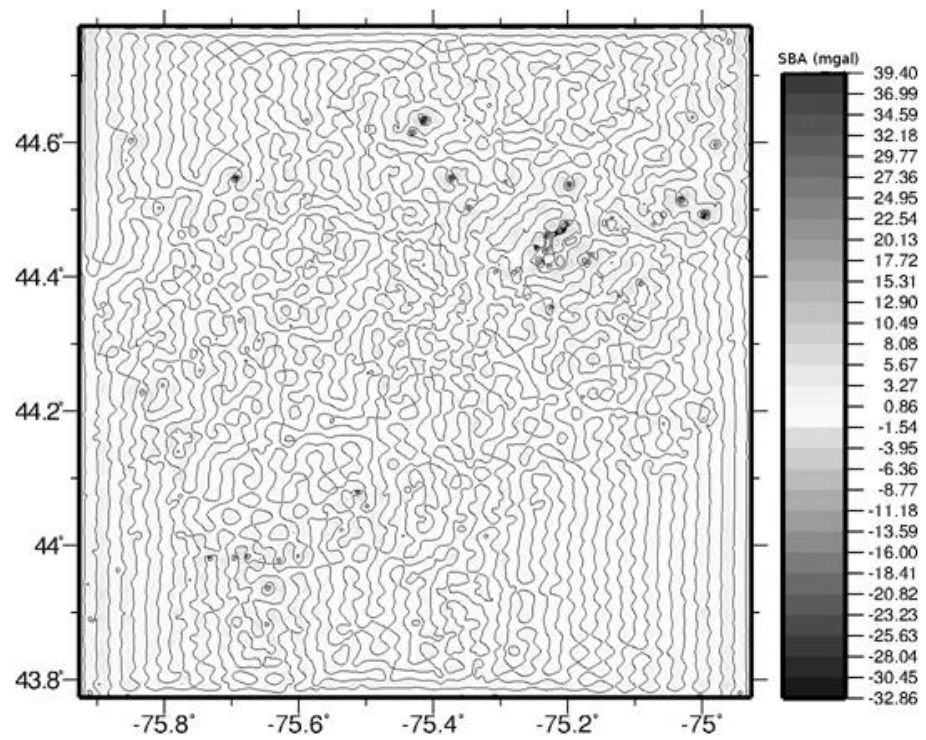

Figure 4d. Superposition of all remaining vertical components (3000 m to $12.95 \mathrm{~m}$ ) above HL2, 1 degree region visually scaled to Figure $1 \mathrm{~b}$

The visual comparisons of residuals filtered over the full 1 degree surface will now be restricted to a central primary region of interest with dimensions of .12 degrees as illustrated by Figure 5a. The visual scale associated with this figure will be used in the relative scaling for all figures displayed over this region. A $3 \mathrm{~km}$ central sub-region of interest centered on the Balmat mine is also indicated. Figure $5 b$ is the .12 degree region for the original interpolation after a local $3^{\text {rd }}$ order polynomial trend has been removed. Figure $5 \mathrm{c}$ is the result of filtering the full reference region between $10000 \mathrm{~m}$ and (essentially) $\mathrm{z}=0$ and then extracting the central primary region. Removal of a local third order trend surface from this filtered residual yields Figure $5 \mathrm{~d}$. The visible differences between Figures 5a and Figure 5c can be understood through the use of such comparative filter steps. These differences can be correlated to the presence of the reflective layer at the base of the CCSZ which immediately underlies the lower depth for Figure $5 \mathrm{c}$. The larger scale information associated with the trend removed from Figure $5 \mathrm{a}$ to produce Figure $5 \mathrm{~b}$ must come from contributions which originate between the depths of $10000 \mathrm{~m}$ and $3000 \mathrm{~m}$. 


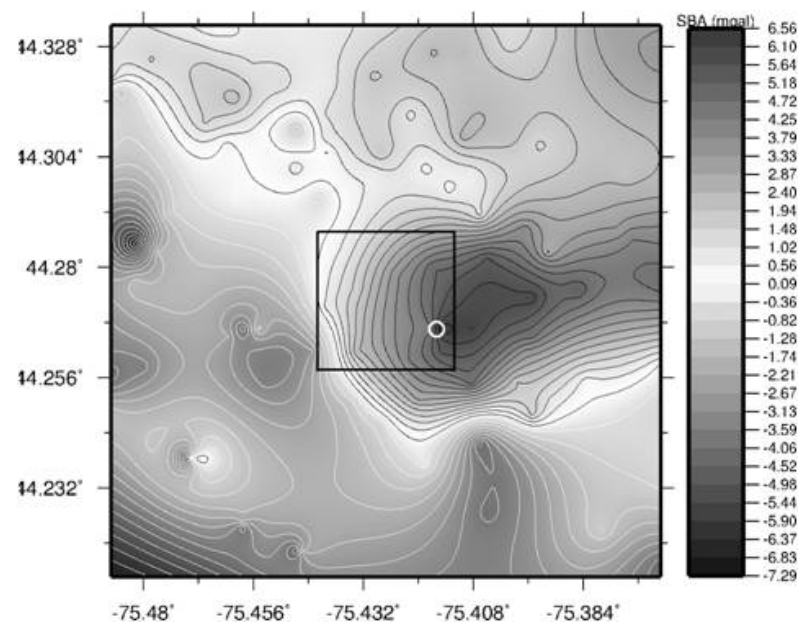

Figure 5a. .12 degree central primary region of interest, extracted from original 1 degree interpolated reference surface no trend removed, absolute visual scale assigned, small white circle centered on a location of interest withina .03 degree central sub-region (indicated)

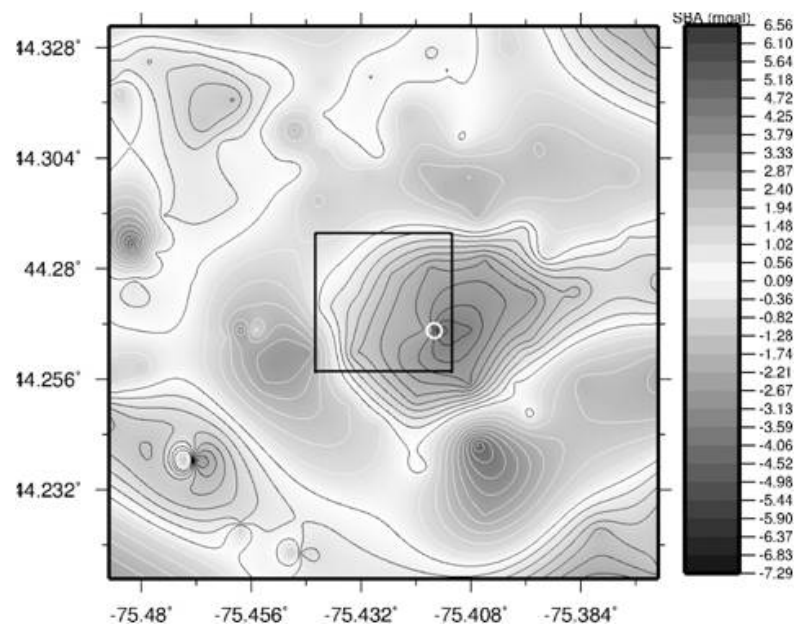

Figure $5 b . .12$ degree central primary region of interest, extracted from original 1 degree interpolated reference surface, localized third order polynomial trend removed, visual scale of Figure 5a assigned, small white circle centered on a location of interest within a .03 degree central sub-region (indicated)

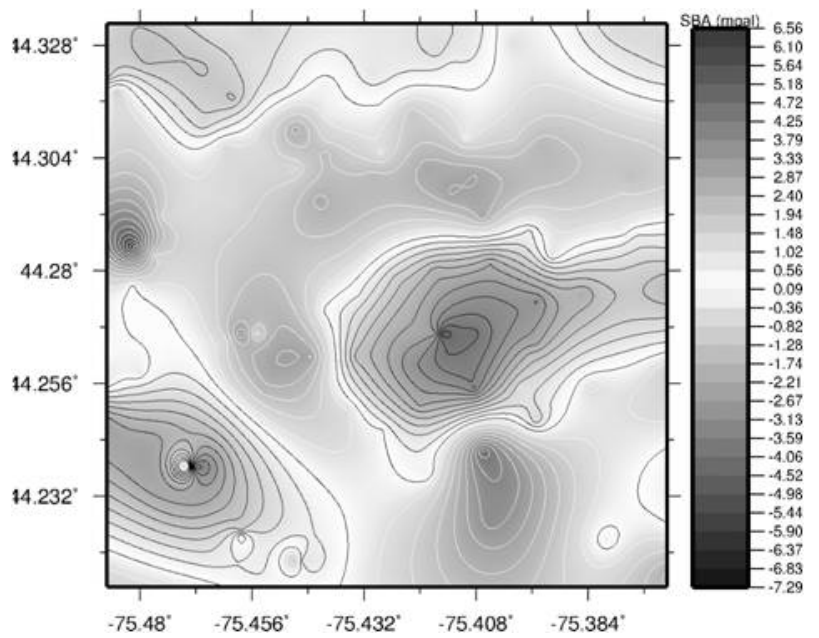

Figure 5c. .12 degree central primary region of interest extracted from 1 degree reference region after filtering between $10000 \mathrm{~m}$ and $\mathrm{z}=0 \mathrm{~m}$, no trend removed, assigned the visual scale of Figure 5a 


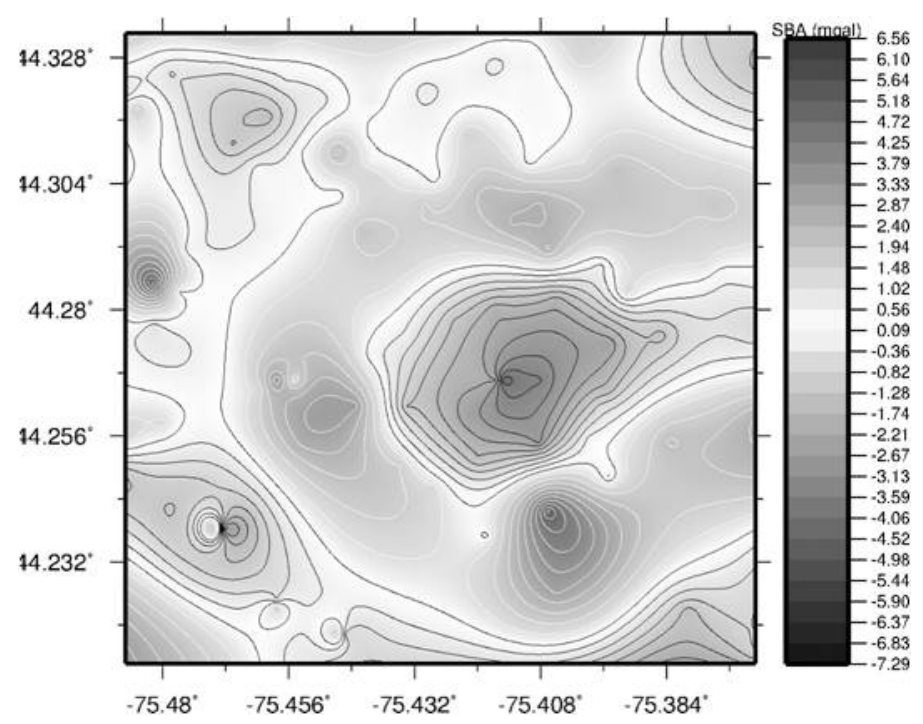

Figure 5d. .12 degree central primary region of interest extracted from 1 degree reference region after filtering between $10000 \mathrm{~m}$ and $\mathrm{z}=0 \mathrm{~m}$, localized third order trend removed, assigned the visual scale of Figure 5a

Figure 6a displays the information from Figure $5 \mathrm{~d}$ overlaid with the contours for the local bedrock stratigraphy (available from the New York State Museum G.I.S. Collection via http://www.nysm.nysed.gov). The same contours and gradient scales have been assigned to all four figures, as described above. A strong visible correlation exists between the bedrock contours and the prominent central anomaly. The small white circle near the SE corner of the $3 \mathrm{~km}$ sub-region in Figures 6a indicates a position at which both the stratigraphy and the gravity contours display a pronounced kink. This is also the location of an interface between contrasting anomalies in shallow, finer scale comparisons (considered below).

The selective superpositions of our filtering operations are continued using the full reference surface to provide a set of 3 partial volume contributions beneath the .12 degree central region. The contributions are isolated between $10000 \mathrm{~m}$ to $5000 \mathrm{~m}$ (Figure 6b), $5000 \mathrm{~m}$ to $3000 \mathrm{~m}$ (Figure 6c), and $3000 \mathrm{~m}$ to z=0 (Figure 6d). The geological units responsible for the bedrock stratigraphy lie well above the dominant contributions in Figure $6 \mathrm{~b}$. The finer details defining the interpolated form of the anomaly in Figure $5 \mathrm{~d}$ are contributed in stages over the intervening 5000 meters, with a significant shift in the scale of these contributions above $3000 \mathrm{~m}$. The positive density central ovoid in Figure $6 \mathrm{~b}$ remains stable against filtering for depth increments of approximately $10 \%$ of the mean depth of each filter. Smaller bandwidths result in leakage contamination which progresses into the primary region and visibly contaminates the information. The $10 \%$ ratio of depth interval to mean depth applied in filtering over the full region can be used to study the evolution of stable intermediate anomalous contributions in the intervals represented by Figures $6 \mathrm{c}$ and $6 \mathrm{~d}$. The stability of the filtered results over these depths should extend out over a central sub-region with dimensions on the order of $30 \mathrm{~km}$ or more, approximately $10 \%$ of the 1 degree reference region.

The vertical resolution improves above $3000 \mathrm{~m}$ as the spacing of the discrete levels decreases with depth. The scale of the included features requires a reduced scale of view, this time to a .03 degree $(\sim 3 \mathrm{~km})$ central sub-region. The ratio of $10 \%$ (interval to mean depth) should again guarantee stability for residuals viewed within the central $10 \%$ of the reference region. The stability against edge effects and aliasing is a result of the extension and resampled interpolation employed in digitizing the original measurements.

It is necessary to consider the features at a finer spatial scale using extremely narrow filter bandwidths. The exclusion of edge effects over the $10 \%$ central region will remain effective down to filter intervals as small as 25-50 m as we approach a depth of $400 \mathrm{~m}$. Residuals below either these depth or interval limits eventually exhibit oscillatory distortion as the aliased information at the center extends out to superpose with the edge effects beyond the central region. The information in residuals for filters narrower than $100 \mathrm{~m}$ cannot be correlated with available geologic information and the contours may not be realistic. The discussion will be restricted to filters representing $200 \mathrm{~m}$ depth intervals for the shallowest considerations which follow. 


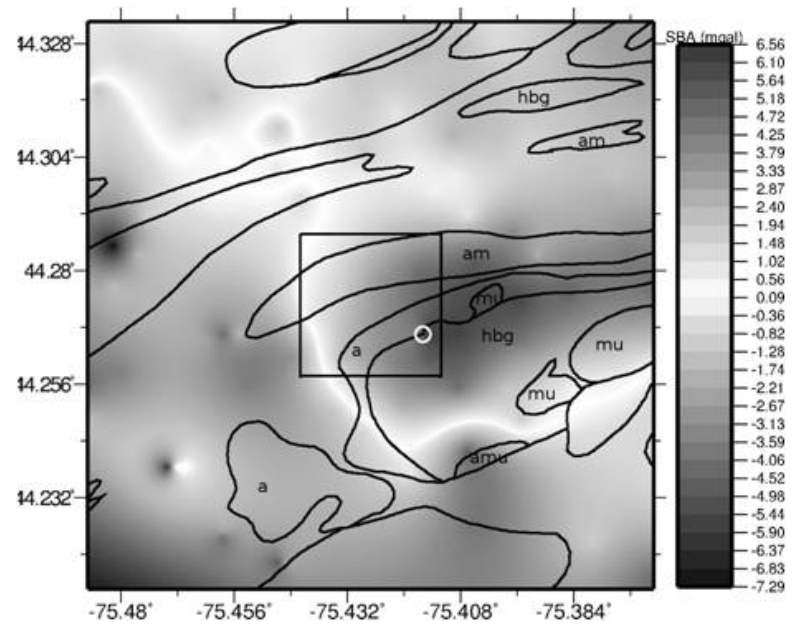

Figure 6a. .12 degree central primary region of interest, removed from 1 degree reference region after filtering between $10000 \mathrm{~m}$ and $\mathrm{z}=0 \mathrm{~m}$, local third order polynomial trend removed, assigned the gradient of Figure 5a, local bedrock stratigraphy in overlay. Center of small white circle indicates a location of interest, .03 degree central subregion indicated

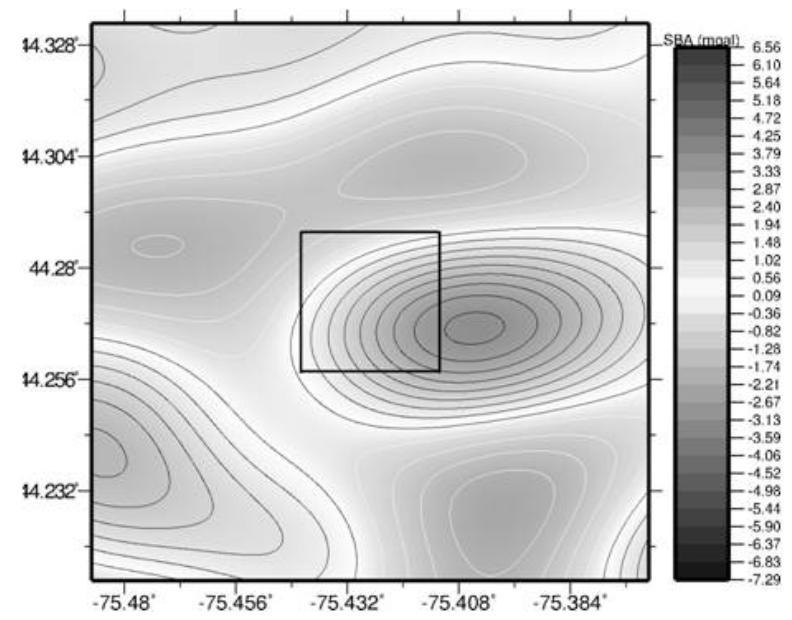

Figure 6 b. .12 degree central primary region of interest, removed from 1 degree reference region after filtering between $10000 \mathrm{~m}$ and $5000 \mathrm{~m}$, local third order polynomial trend removed, assigned the visual scale of Figure $5 \mathrm{a}, .03$ degree central sub region indicated

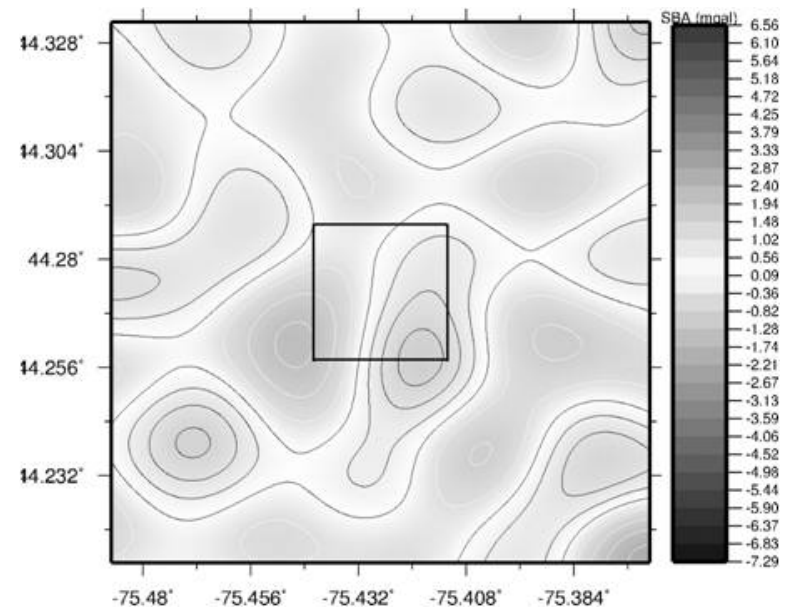

Figure 6c. .12 degree central primary region of interest, removed from 1 degree reference region after filtering between $5000 \mathrm{~m}$ and $3000 \mathrm{~m}$, local third order polynomial trend removed, assigned the visual scale of Figure $5 \mathrm{a}, .03$ degree central sub region indicated 


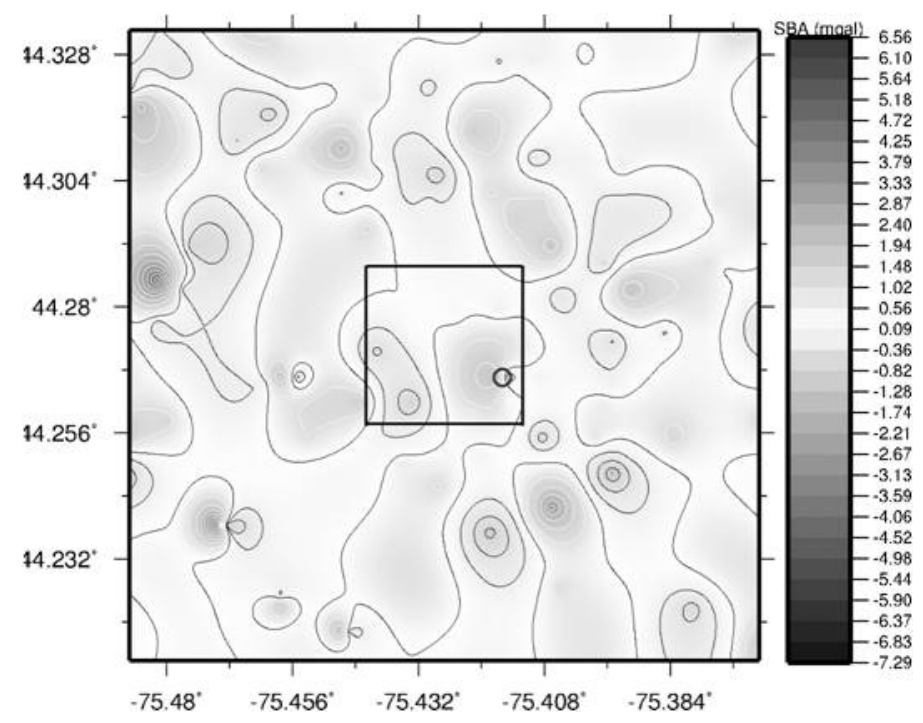

Figure $6 \mathrm{~d}$. .12 degree central primary region of interest, removed from 1 degree reference region after filtering between $3000 \mathrm{~m}$ and $\mathrm{z}=0 \mathrm{~m}$, local third order polynomial trend removed, assigned the visual scale of Figure

$5 \mathrm{a}, .03$ degree central sub region indicated

Figure 7a displays the .03 degree central region for the original interpolation with an absolute gradient and contours. A local third order trend has been removed in order to reveal the higher wavenumber (finer scale) features of the relevant source contributions in Figure $7 \mathrm{~b}$. A residual surface resulting from an appropriate filtering procedure over the depths from $3000 \mathrm{~m}$ to the highest wavenumber, associated with the near surface or $\mathrm{z}$ $=0$, is shown in Figure $7 \mathrm{c}$. Figures $7 \mathrm{~b}$ and $7 \mathrm{c}$ are scaled visually to Figure $7 \mathrm{a}$. We have displayed the residual of Figure $7 \mathrm{c}$ using an absolute visual scale in Figure $7 \mathrm{~d}$. A third order localized polynomial trend is removed and from this residual and assigned the same contour levels and gradient scale (Figure 7e). Figure $7 \mathrm{f}$ is the information within Figure $7 \mathrm{~b}$ viewed with the visual scale of Figure $7 \mathrm{~d}$. These procedures confirm that the filtering procedures we have applied for the views over this central sub-region include only source contributions from above the depth of HL2.

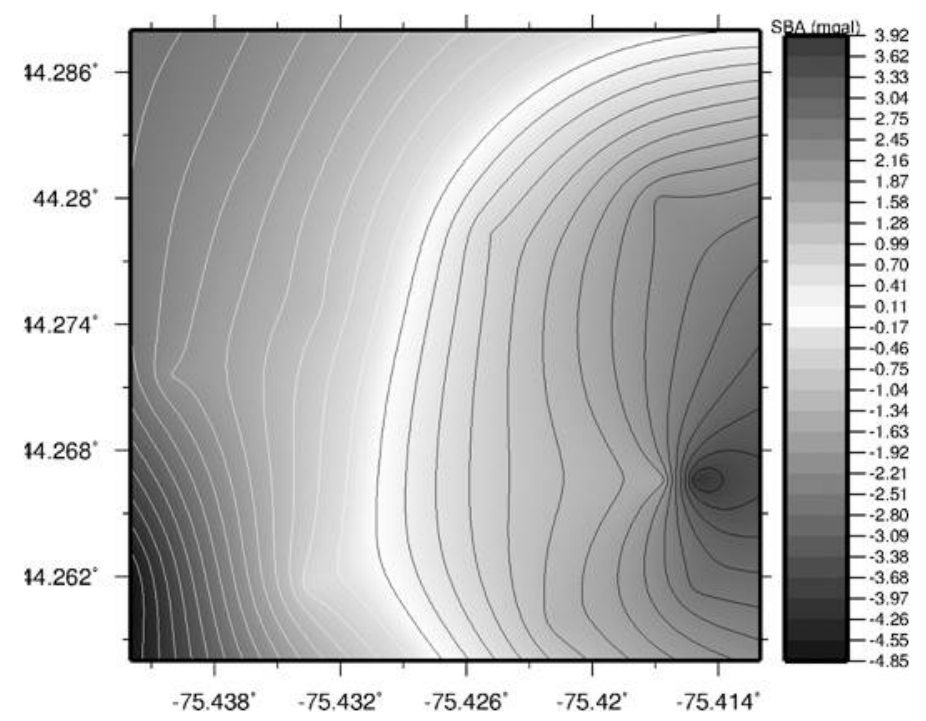

Figure $7 \mathrm{a} . .03$ degree central sub-region of the primary region of interest, removed from interpolated but not filtered 1 degree reference region, no trend removed, assigned an absolute visual scale 


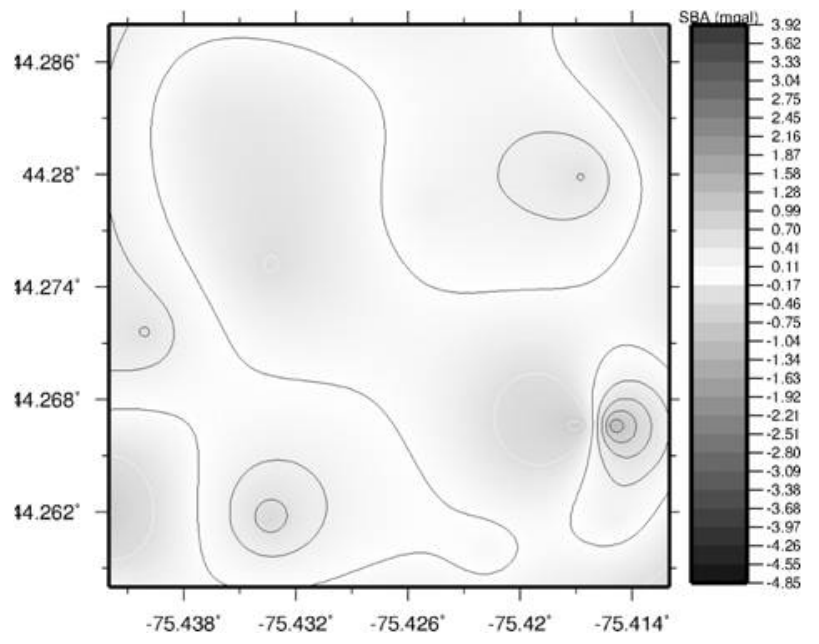

Figure $7 \mathrm{~b} . .03$ degree central sub-region of the primary region of interest, removed from interpolated but not filtered 1 degree reference region, local third order polynomial trend removed, assigned the visual scale of

Figure $7 \mathrm{a}$

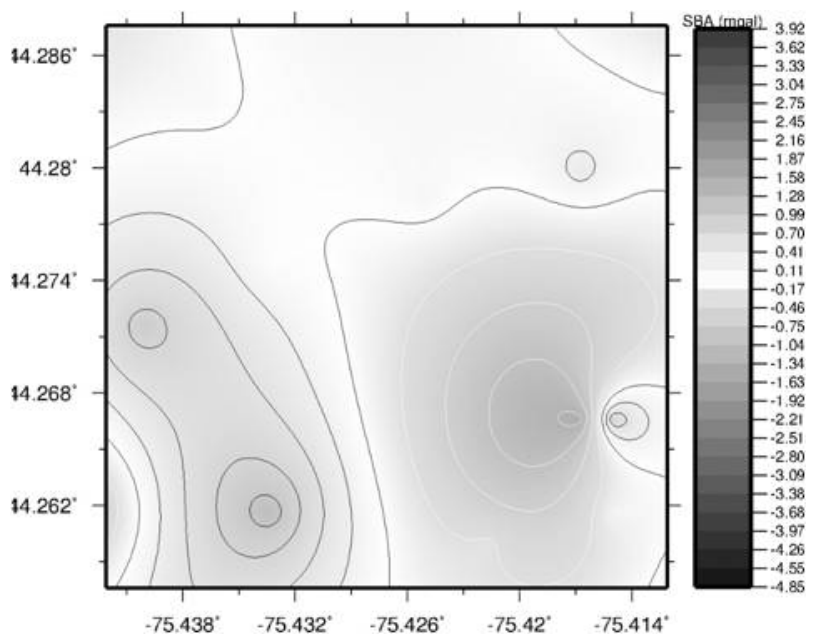

Figure 7 c. .03 degree central sub-region of the primary region of interest, removed from 1 degree reference region after filtering from $3000 \mathrm{~m}$ to $\mathrm{z}=0$, no trend removed, assigned the visual scale of Figure $7 \mathrm{a}$

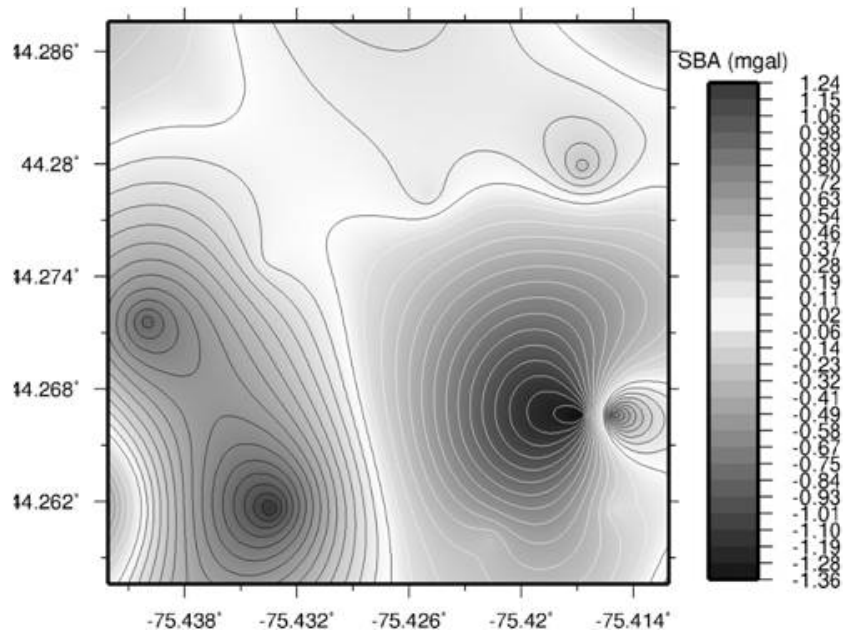

Figure 7 d. .03 degree central sub-region of the primary region of interest, removed from 1 degree reference region after filtering from $3000 \mathrm{~m}$ to $\mathrm{z}=0$, no trend removed, absolute visual scaling 


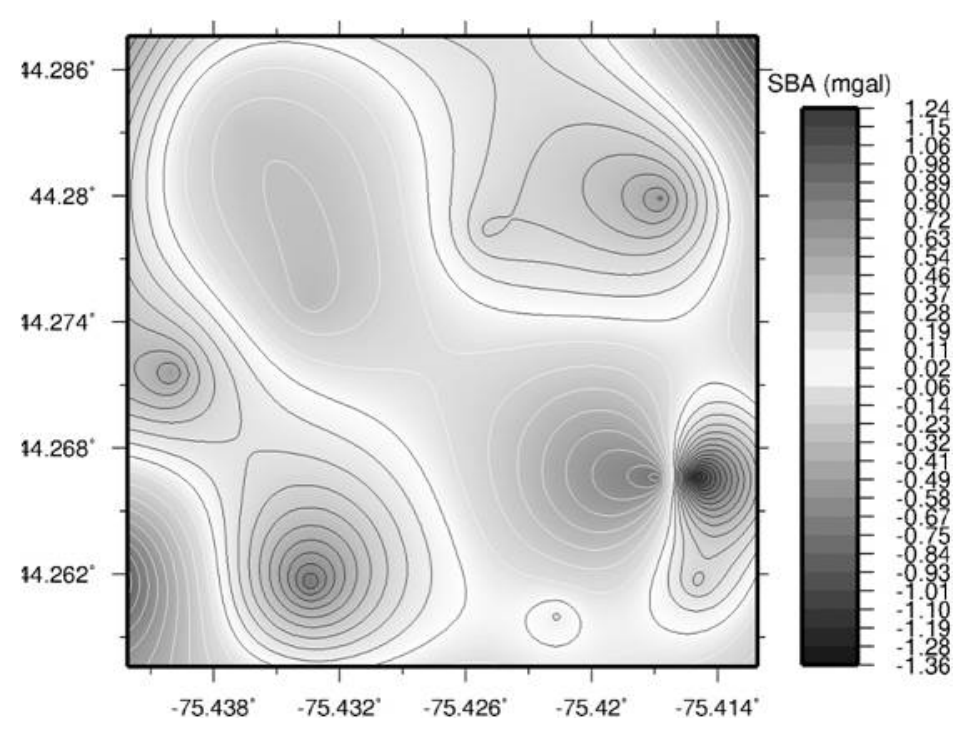

Figure $7 \mathrm{e} .03$ degree central sub-region of the primary region of interest, removed from 1 degree reference region after filtering from $3000 \mathrm{~m}$ to $\mathrm{z}=0$, no trend removed, assigned the visual scale of Figure $7 \mathrm{~d}$

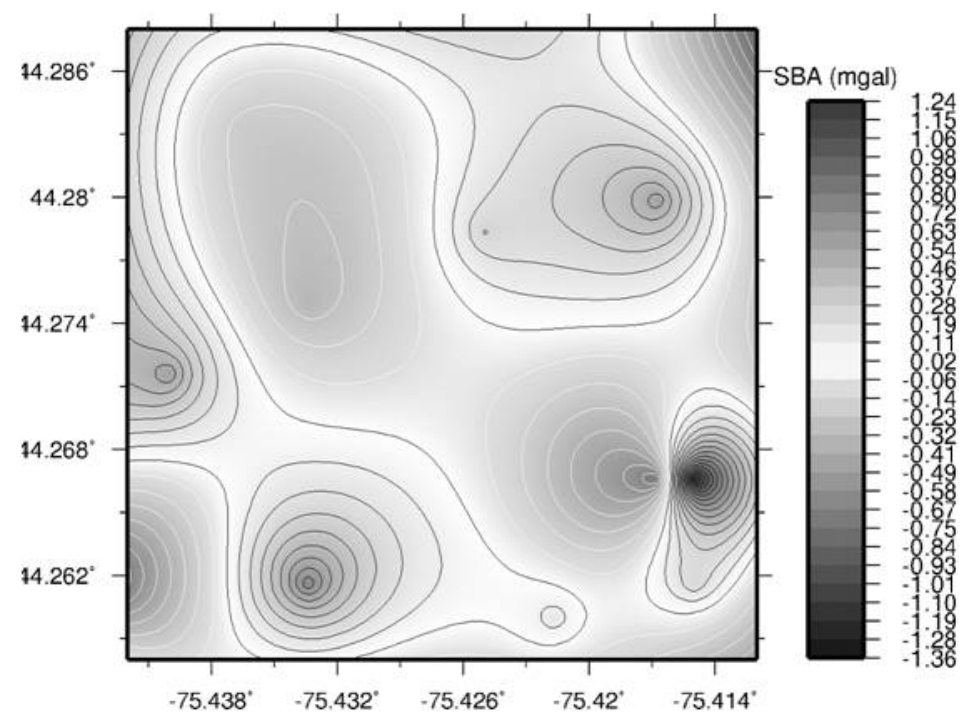

Figure $7 \mathrm{f} . .03$ degree central sub-region of the primary region of interest, removed from interpolated but not filtered 1 degree reference region, local third order polynomial trend removed, assigned the visual scale of Figure $7 \mathrm{~d}$

Information concerning the geology in the depths from $3000 \mathrm{~m}$ to $1600 \mathrm{~m}$ is not readily available for this area. Detailed information on the geology above 1600 meters exists. This is based primarily upon 30 years of commercial drilling and the characterization of core samples from a local mine as reported by deLorraine (2001). Comparisons can be made with information from the scaled illustrations in Figure 8 adapted from deLorraine (figures and data from private communications, 2002). Figure 8 (top) is a cross sectional view of the local stratigraphy at the latitude of Balmat Mine Shaft \#4. Horizontal lines indicating 200 meter depth increments from the surface down to 1600 meters and extending westward from the longitude of the $\# 4$ shaft have been added as a depth reference. Figure 8 (bottom) is a projected surface footprint of major mine features, exploited ore bodies, and mine shaft locations. This information was digitized and georeferenced to serve as spatial reference guides. 

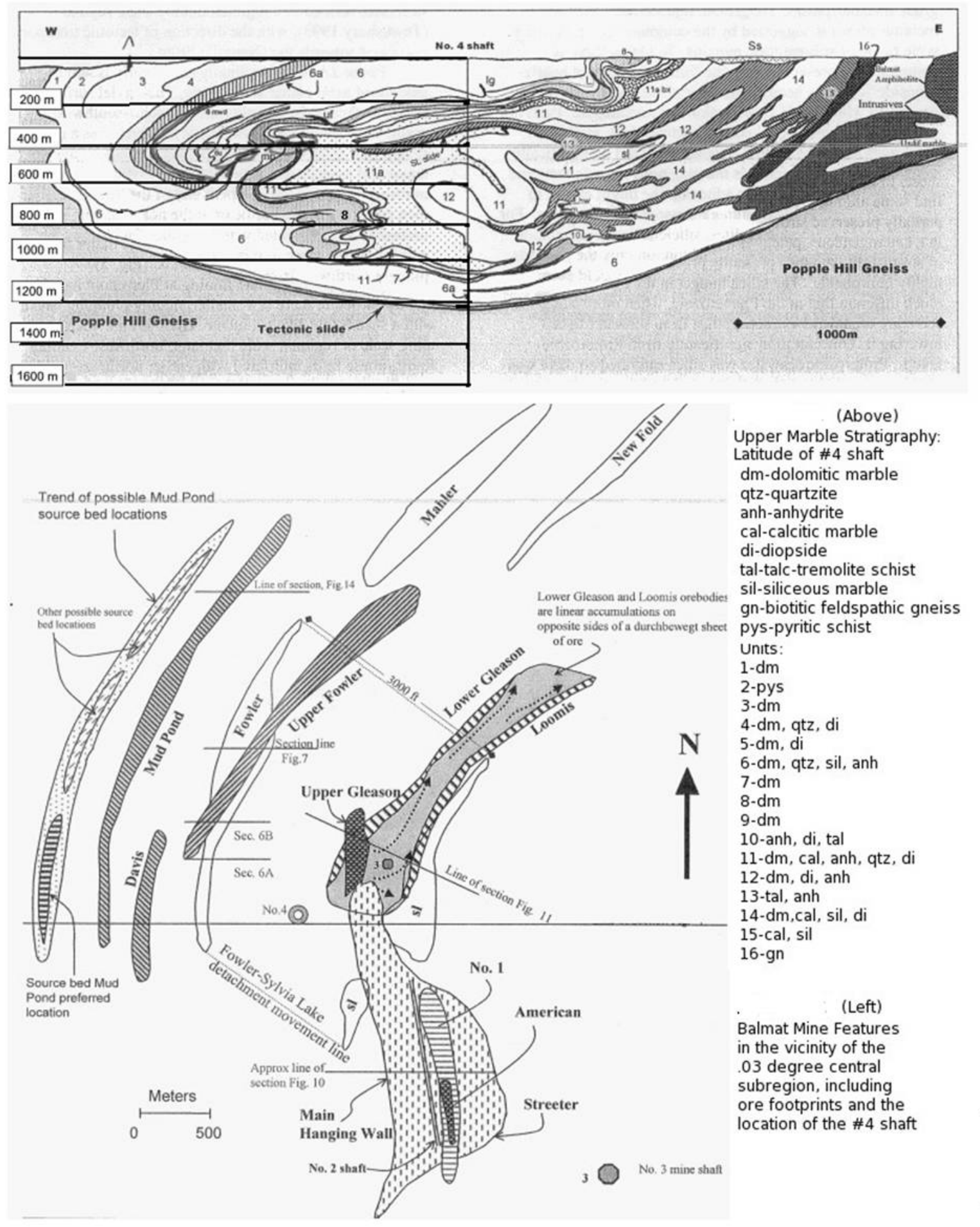

Figure 8. Surface features and stratigraphy of the Sylvia Lake Syncline and Balmat zinc mine, captions embedded

Figure 9a is the residual for this area taken from a 1 degree region FFT filter over the depths from $1600 \mathrm{~m}$ to $\mathrm{z}=$ 0 . The contours and gradient for this figure are absolute. These will be applied in relative scaling for the presentation of all the remaining residual figures in this discussion. The next two figures, $9 \mathrm{~b}$ and $9 \mathrm{c}$, are the residual sub-regions for filters over the full 1 degree region from $1600 \mathrm{~m}$ to $400 \mathrm{~m}$ and from $400 \mathrm{~m}$ to $\mathrm{z}=0$ respectively, visually scaled to Figure 9a. Figure 9c reveals that our interpolation has resulted in very high 
wavenumber aliasing as it fails to include any useful information concerning the sources above $400 \mathrm{~m}$. The localized contours around every actual sampled location increase in number and intensity as we try to apply narrower filters over this depth range. Away from these locations the surface becomes normal, i.e. approaches a constant value of zero.

Figure $9 \mathrm{~d}$ is represents the local contributions revealed by filtering the 1 degree region over depths from $1600 \mathrm{~m}$ to $1200 \mathrm{~m}$. Figure 9e represents the local features revealed by filtering between $1200 \mathrm{~m}$ and $400 \mathrm{~m}$ depths. The black outlines of the footprint for the exploited ore bodies are combined with the location of the Number 4 mine shaft (white square in the SE) to provide a spatial reference over the surfaces. The locations of the original survey stations are also indicated (green diamonds). The upper case letters here and in the ensuing figures mark features which can be used to trace the evolution of the source contributions across a localized transition in the depths between $1400 \mathrm{~m}$ and $1200 \mathrm{~m}$. It is at this depth that Popple Hill gneiss is replaced by the marble units which are characteristic of the Sylvia Lake Syncline across the view. Figures 9d and 9e illustrate that features A and $\mathrm{B}$ are both present below $1200 \mathrm{~m}$, but only feature $\mathrm{A}$ is visible within the features at depths above the transition into the marble units. Feature $\mathrm{C}$ indicates one of the two sets of contours responsible for the kink in the gravity contours mentioned above for views of deeper contributions over larger central regions. These contributions commence only above the transition into the marble and then continue to the surface. Features D and $\mathrm{E}$ are not visible in Figure 9c but persist through decreased depths above the gneiss contributions in Figure 9e. This is illustrated in the next set of figures.

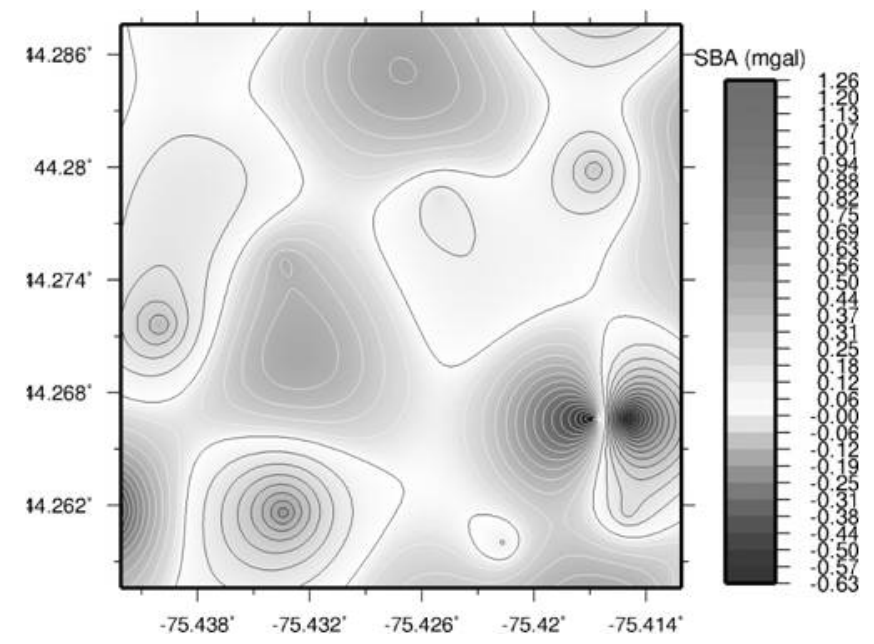

Figure 9a. .03 degree region from 1 degree reference filtered between $1600 \mathrm{~m}$ and $\mathrm{z}=0$ depths, absolute visual scaling

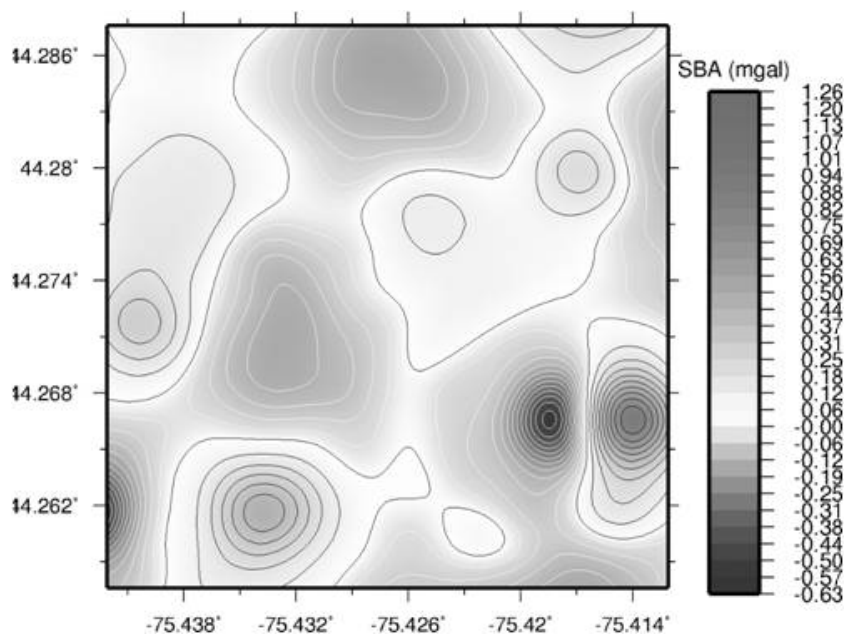

Figure 9b. .03 degree region from 1 degree reference filtered between $1600 \mathrm{~m}$ and $400 \mathrm{~m}$ depths, visual scaling of Figure 9a 


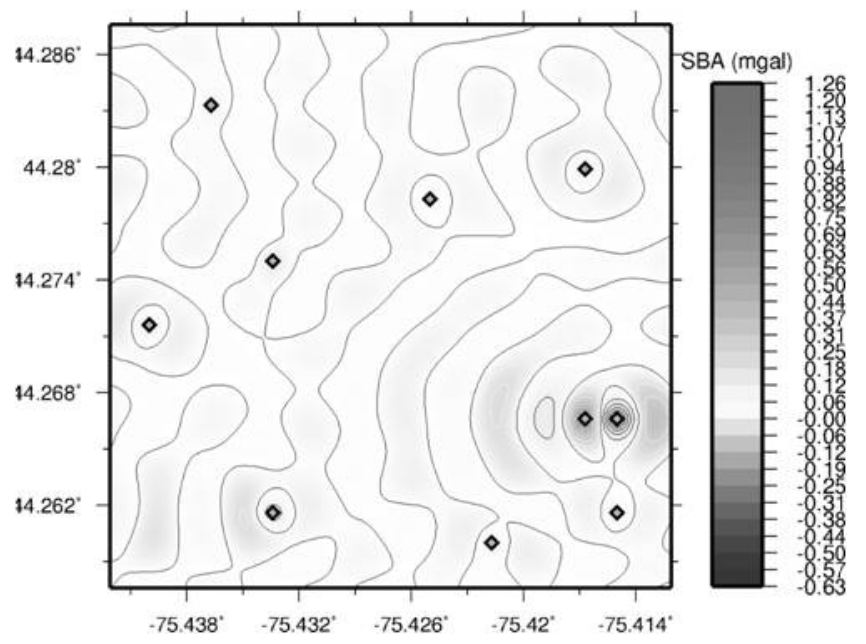

Figure 9c. .03 degree region as ion Figure 9a filtered between $400 \mathrm{~m}$ and $\mathrm{z}=0$ from 1 degree reference region, visual scale of Figure 9a

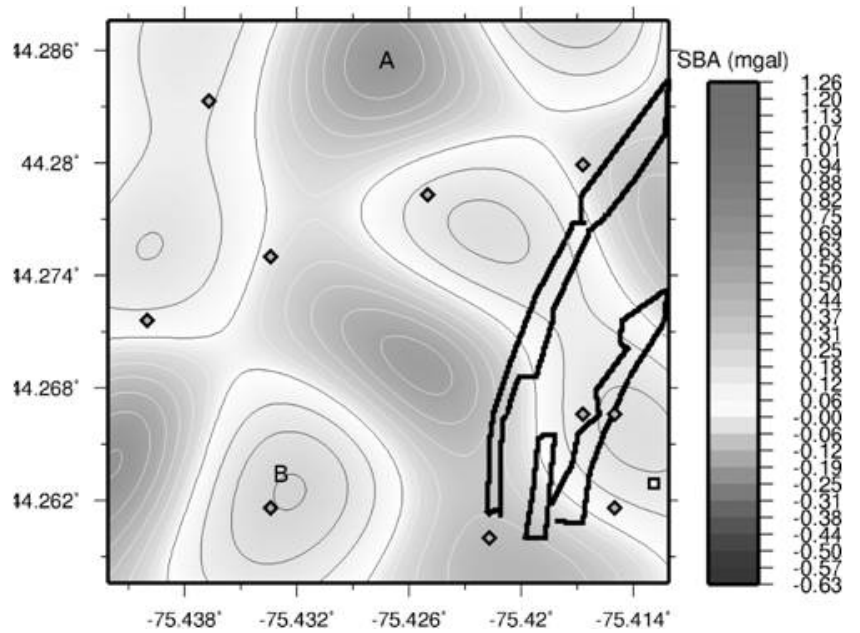

Figure 9d. .03 degree region filtered from 1 degree reference over depths $1600 \mathrm{~m}$ to $1200 \mathrm{~m}$ (gneiss->marble transition), visually scaled to Figure 9a, ore footprints (black), station locations (diamonds), \#4 mine shaft (white square to SE), and features from discussion (upper case letters)

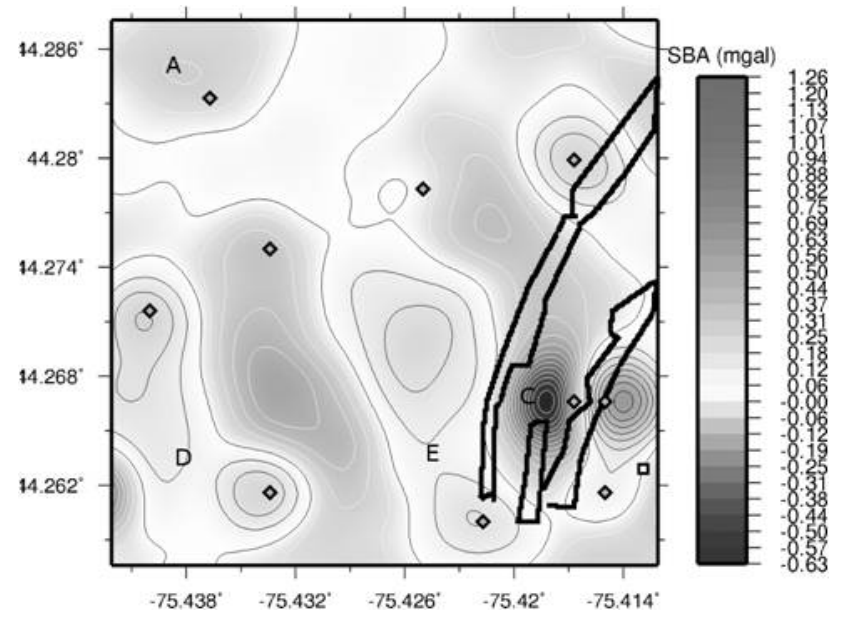

Figure 9e. .03 degree region filtered from 1 degree reference over depths $1200 \mathrm{~m}$ to $400 \mathrm{~m}$ (volume included within Figure 8) visually scaled to Figure 9d, ore footprints (black), station locations (diamonds), \#4 mine shaft (white square to SE), and features from discussion (upper case letters) 
Figures 10a-10d display the evolution of the Balmat sources in 200 meter depth increments over the 800 meters of reliable interpolated information between $1200 \mathrm{~m}$ and $400 \mathrm{~m}$. The feature labeled $\mathrm{C}$ is situated approximately at the location of unit 8 (dolomitic marble + diopside + anhydrite) in Figure 8 (top). The dimensions across the associated contours are on the order of the average dimensions of unit 8 as indicated by the scale in Figure 8 (top). The density contrasts between this unit (dolomitic marble) and the strata between which it is located were reported for a related figure in deLorraine (2001). These are consistent with the relative densities which can be estimated for feature $\mathrm{C}$, its associated high gravity anomaly, and feature $\mathrm{E}$ to the west. The evolution of these contours as the depth decreases remains consistent with the spatial shifts of the related source bodies. These can be evaluated qualitatively using Figure 8 (top).

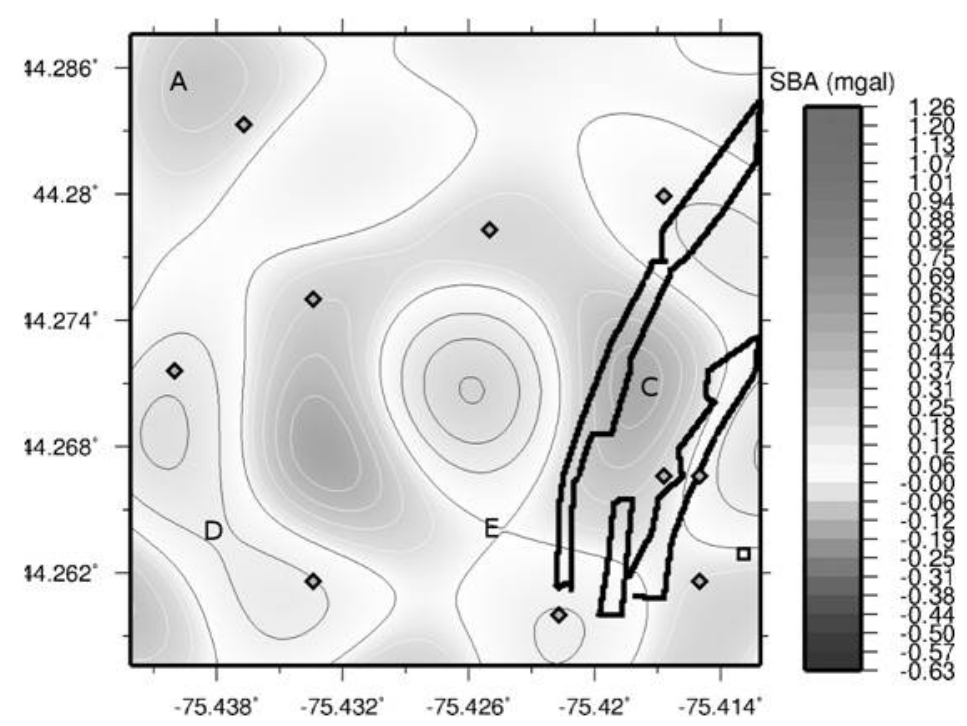

Figure 10a. .03 degree region filtered from 1 degree reference over depths $1200 \mathrm{~m}$ to $1000 \mathrm{~m}$ (volume included within Figure 8) visually scaled and referenced as Figure 9d

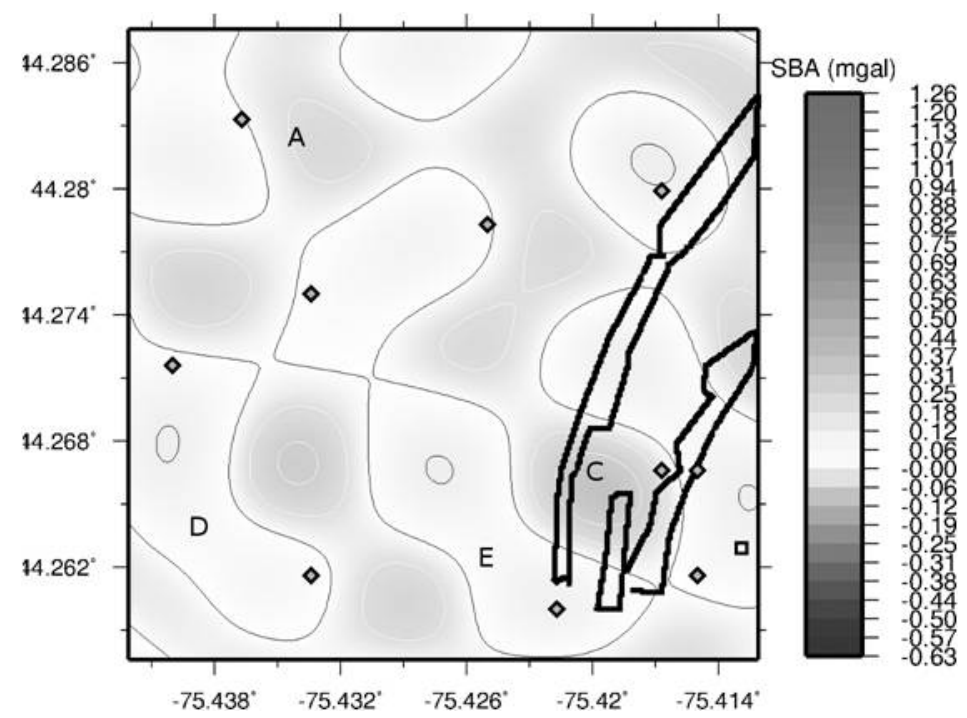

Figure 10b. .03 degree region filtered from 1 degree reference over depths $1000 \mathrm{~m}$ to $800 \mathrm{~m}$ (volume included within Figure 8) visually scaled and referenced as Figure 9d 


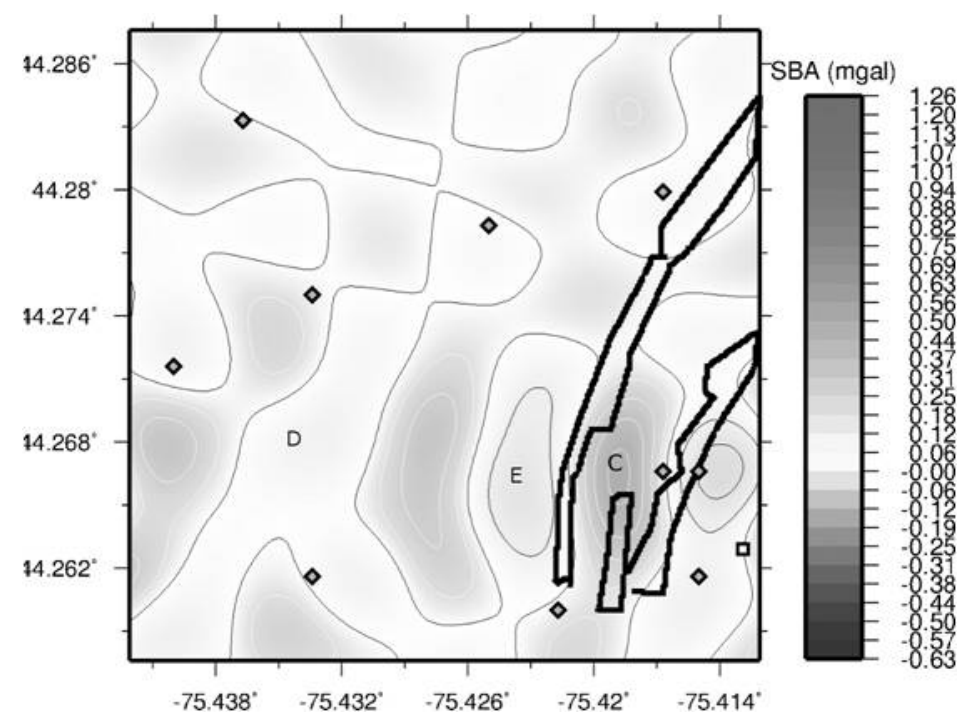

Figure 10c. .03 degree region filtered from 1 degree reference over depths $800 \mathrm{~m}$ to $600 \mathrm{~m}$ (volume included within Figure 8) visually scaled and referenced as Figure 9d

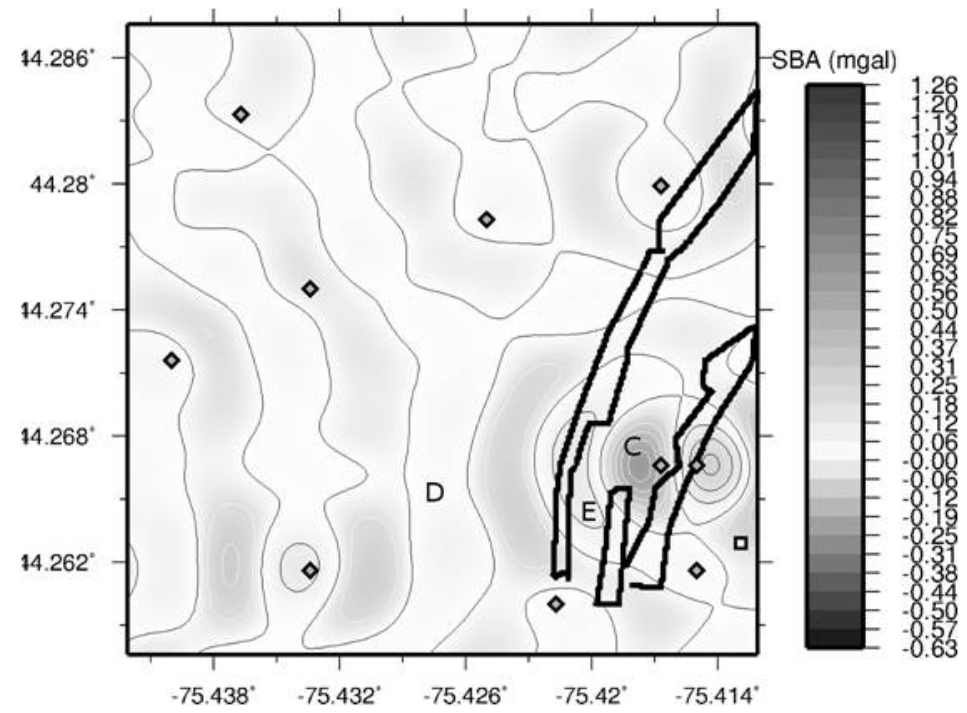

Figure 10d. .03 degree region filtered from 1 degree reference over depths $600 \mathrm{~m}$ to $400 \mathrm{~m}$ (volume included within Figure 8) visually scaled and referenced as Figure 9d

\section{Conclusions}

Fast Fourier transform separation protocols for digital representations of the near surface attraction due to the Earth's scalar potential fields have been developed. These are based upon the scaled application of conventional methods for data acquisition and analysis. The approach eliminates or reduces the dependencies upon a priori information and subjective geological considerations which are characteristic of conventional approaches to analysis. The techniques are founded in the fundamental properties of the physical forces responsible for the field measurements and the mathematical properties of the FFT. The techniques rely upon visual inspection and comparison of filtered spatial transforms. Density or magnetization estimates can be derived through simple statistical calculations involving the distribution of values within a transform.

The methods require an understanding of the advantages which can be gained through considered digital resampling of the information associated with the original field survey. They are based upon an objectively quantified extension of the record length employed in the sampling. This extension has been applied in accord with a generalized scaling relationship which characterizes the spacing of the discrete vertical components in a two dimensional spectral array. The values of the elements within these arrays reflect the length scales associated 
with the digital surface representing the information related to source contributions to the original field measurements.

Implementation of these methods requires only a general understanding of the characteristics of the physical potentials and mathematical transformations, a modest level of technical skill, and a minimal commitment of resources. The necessary software and hardware technologies have been available for nearly two decades. The approach can be automated with simple scripts for convenience and efficiency. It complements and extends conventional methods of analysis by providing the means to reduce the ambiguity associated with modeling, inversion, and interpretation. It is therefore compatible with the goals and resources of any related investigation.

The most significant advantage provided by the methods come from the predictable consequences of employing regularly spaced station locations, appropriately scaled region extension, and properly resampled interpolations. A set of regular measurements can be acquired with a known spatial accuracy and detector sensitivity over a properly chosen reference region. Surveys can be designed or augmented in order to target particular localized regions or interesting depths. The depth intervals used for filtering analysis can be selected based upon the scaled central sub-regions and depths of interest in order to maximize the valid, distortion-free information. The results can be compared and correlated with existing or suspected geology within the volume(s) of interest. They can be used directly to supply reliable estimates to modeling and inversion studies. They can be analyzed further with conventional spectral or spatial analytical methods. The scaled increase in valid information leads to a proportionally scaled decrease in the ambiguity in the final interpretations. The approach as described amounts to an objective and optimized three dimensional spatial isolation of the source information contained within the digital representation of a potential field survey.

\section{Acknowledgements}

We wish to thank Bob and Joe for their enthusiasm and editorial assistance. The authors acknowledge the valuable insights and perspective provided by Dr. Raoul T. Mitgong, friend and colleague.

\section{References}

Beltrão, J. F., \& Silva, J. B. C. (1993). Mapping and depth ordering of residual gravity sources. Geophysics, 58, 1408-1416. http://dx.doi.org/10.1190/1.1443356

Bhattacharrya, B. K. (1967). Some general properties of potential fields in space and frequency domain: a review. Geoexploration, 5, 127-143. http://dx.doi.org/10.1016/0016-7142(67)90021-X

Blakely, R. J. (1996). Potential theory in gravity \& magnetic applications. Cambridge University Press, Cambridge (UK). ISBN 0-521-57547-8.

Cooley, J. W., \& Tukey, J. W. (1965). An algorithm for the machine calculation of complex Fourier series. Mathematics of computation, 19(90), 297-301. http://dx.doi.org/10.2307/2003354

Cowan, D., \& Cooper, G. (2005). Separation filtering using fractional order derivatives. Exploration Geophysics, 36(4), 393-396. http://dx.doi.org/10.1071/EG05393

DeLorraine, W. (2002). Private communications (November). Additional unpublished figures and information.

DeLorraine, W. (2009, March). High Grade Metamorphism, Remobilization, and Polydeformation of the Balmat Zinc Sulfide Deposits, Nw Adirondacks, New York State. In Geological Society of America Abstracts with Programs, (Vol. 41, No. 3, p. 84).

DeLorraine, W. F. (2001). Metamorphism, polydeformation, and extensive remobilization of the Balmat zinc orebodies, northwest Adirondacks. New York: Society of Economic Geologists Guidebook Series, 35, 25-54.

DeLorraine, W. F., \& Sangster, A. L. (1997). Geology of the Balmat Mine. In Geological Association of Canada-Mineralogical Association of Canada Joint Annual Meeting.

Heumann, M. J., Bickford, M. E., Hill, B. M., McLelland, J. M., Selleck, B. W., \& Jercinovic, M. J. (2006). Timing of anatexis in metapelites from the Adirondack lowlands and southern highlands: A manifestation of the Shawinigan orogeny and subsequent anorthosite-mangerite-charnockite-granite magmatism. Geological Society of America Bulletin, 118(11-12), 1283-1298. http://dx.doi.org/10.1130/B25927.1

Hinze, W. J. (1990). The role of gravity and magnetic methods in engineering and environmental studies. Geotechnical and environmental geophysics, 1, 75-126.

Hornby, P., Boschetti, F., \& Horowitz, F. G. (1999). Analysis of potential field data in the wavelet domain. Geophysical Journal International, 137(1), 175-196. http://dx.doi.org/10.1046/j.1365-246x.1999.00788.x 
Hughes, S., \& Luetgert, J. H. (1992). Crustal structure of the southeastern Grenville Province, northern New York State and eastern Ontario. Journal of Geophysical Research: Solid Earth (1978-2012), 97(B12), 17455-17479. http://dx.doi.org/10.1029/92JB01793

Knight, R. H. (2005). Recent zinc ore discoveries in the Balmat-Edwards District, northwest Adirondacks, New York State; a case history: Geological Society of America Abstracts with Programs, 44th annual meeting, v. 37, p. 64.

Li, Y., \& Oldenburg, D. W. (1998). Separation of regional and residual magnetic field data. Geophysics, 63(2), 431-439. http://dx.doi.org/10.1190/1.1444343

Mallick, K., \& Sharma, K. K. (1997). Computation of regional gravity anomaly-A novel approach. Proceedings of the Indian Academy of Sciences-Earth and Planetary Sciences, 106(1-2), 55-59.

McDermott, A. M. (2006). Method for enhancing depth and spatial resolution of one and two dimensional residual surfaces derived from scalar potential data. U.S. Patent 7043366, Canadian Patent 2456459 (2009).

McDermott, A. M., \& Chiarenzelli, J. R. (2013). Quantization Within the Spectral and Spatial Transforms of Sampled Source Contributions to Geophysical Scalar Potential Fields and Its Significance for Education, Research, and Resource Exploration. Modern Applied Science, 7(8). http://dx.doi.org/10.5539/mas.v7n8p31

McLelland, J., Selleck, B., \& Bickford, M. E. (2010). Review of the Proterozoic evolution of the Grenville Province, its Adirondack outlier, and the Mesoproterzoic inliers of the Appalachians. In R. P. Tollo., M. J. Bartholomew, J. P. Hibbard, \& P. M. Karabinos (Eds.), From Rodinia to Pangea: The Lithotectonic Record of the Appalachian Region (Vol. 206, pp. 1-29), Geological Society of America Memoir.

Mishra, D. C., \& Tiwari, V. M. (2011). Encyclopedia of solid earth geophysics. In H. K. Gupta (Ed.), Dordrecht (p. 513). Springer, The Netherlands.

Paterson, N. R., \& Reeves, C. V. (1985). Applications of gravity and magnetic surveys; the state-of-the-art in 1985. Geophysics, 50(12), 2558-2594. http://dx.doi.org/10.1190/1.1441884

Rauth, M., \& Strohmer, T. (1998). Smooth approximation of potential fields from noisy scattered data. Geophysics, 63(1), 85-94. http://dx.doi.org/10.1190/1.1444330

Revetta, F. A., \& McDermott, A. M. (2003). The compilation and preparation of high-resolution gravity data for petroleum exploration in New York State and adjoining regions. New York State Energy Research Development Authority (NYSERDA) PON\# 715-02.

Selleck, B. W., McLelland, J. M., \& Bickford, M. E. (2005). Granite emplacement during tectonic exhumation: The Adirondack example. Geology, 33(10), 781-784. http://dx.doi.org/10.1130/G21631.1

Shannon, C. E. (1949). Communication in the presence of noise. Proceedings of the IRE, 37(1), 10-21. http://dx.doi.org/10.1109/JRPROC.1949.232969

Sharma, P. V. (1997). Environmental and engineering geophysics. Cambridge University Press.

Whelan, J. F., \& Rye, R. O. (1984). The Balmat-Edwards zinc-lead deposits; synsedimentary ore from $\begin{array}{lllll}\text { mississippi valley-type fluids. Economic } & \text { Geology, }\end{array}$ http://dx.doi.org/10.2113/gsecongeo.79.2.239

Wiener, R. W. (1983). Adirondack Highlands-Northwest Lowlands "boundary": A multiply folded intrusive contact with fold-associated mylonitization. Geological Society of America Bulletin, 94(9), 1081-1108. http://dx.doi.org/10.1130/0016-7606(1983)94<1081:AHLBAM>2.0.CO;2

\section{Appendix}

The command line programs below are members of the GMT suite of tools (http://gmt.soest.hawaii.edu).

The file blmtdata.csv contains a space delimited array of values (longitude latitude sba) representing the locations and values of the corrected field measurements illustrated in Figure 1a of the main text (double precision decimal form). The first step is interpolation to a regular grid (single precision) over a 1 degree reference region (note: trailing backslash ' $\backslash$ ' indicates a line continuation). The file prefix 'pmp5' denotes a square region with a half-width +-.5 degrees centered on $(-74.977,44.723)$ within the Balmat zinc mine in upstate NY.

The use of ' 1000 ' or ' 10000 ' in a name, e.g. blmtrealto10000, denotes the final number of grid points on a side 
(minus 1), corresponding here to $100,020,001$ array points. The computations can be done efficiently with a PIIITM processor and sufficient memory to calculate the surface ( . 5 Gigabytes).

The greatest limitations on the accuracy and reliability of these methods are the sensitivity, spacing, and extent of the datum included. The computational error of the tools is always contained within the least significant digit at single precision.

blockmean blmtdata.csv -I.001/.001 -R-75.927/-74.927/43.773/44.773 > blmtSBA001.txt

The survey was extracted from a set including both regional datum $(\sim 1-4 \mathrm{~km}$ spacing on average over selected sub-regions) and those from follow-up traverses at the $100 \mathrm{~m}$ scale. The initial interpolation guaranteed that all the stations influence the values in the subsequent resampling over a 5\% larger region. Remove the extra area deliberately included to guarantee smooth termination of the sampled data.

surface blmtSBA001.txt-GBIG_blmtrealto10000.grd -I.0001/.0001 -R-75.977^

$-74.877 / 43.723 / 44.823-\mathrm{T} .25-\mathrm{Z1}$

grdcut BIG_blmtrealto10000.grd -Gpmp5_blmtrealto10000.grd -R-75.927/-74.927/43.773/44.773

Prepare another surface through removal of a $3^{\text {rd }}$ order polynomial trend $(-\mathrm{N} 10=10$ parameter fit $)$.

grdtrend pmp5_blmtrealto10000.grd -N10 -Dpmp5_blmtrealto10000_mt.grd $\backslash$

-Tpmp5_blmttrend10000.grd

Filter the data representing the original unmodified information (pmp5_blmtrealto10000.grd from above) over a depth interval from $1.6 \mathrm{~km}$ up to a distance $400 \mathrm{~m}$ from the surface $(\mathrm{z}=0)$, with sharp cut-offs (no tapering) and without removing a linear trend (-L), then remove a third order trend from the residual ( $\mathrm{mt}$ )

grdfft pmp5_blmtrealto10000.grd -Gpmp5_blmtrealto10000_1600-400m.grd -L।

$-F 1600 / 1600 / 400 / 400$

grdtrend pmp5_blmtrealto10000_1600-400m.grd -N10 -Dpmp5_blmtrealto10000_1600\

-400m_mt.grd -Tpmp5_blmttrend10000_1600-400m.grd

Remove a central sub-region .12 degrees on a size $(>\sim 1 \%$ of the full area) from the original reference surface and the filtered surface, and another sub-region approximately $3 \mathrm{~km}$ ( .03 degrees) on a side as well.

grdcut pmp5_blmtrealto10000.grd -Gpmp06_blmtrealto10000.grd -R-75.487/-75.367/44.213/44.333

grdcut pmp5_blmtrealto10000_1600-400m.grd -Gpmp06_blmtrealto10000_1600-400m.grd -R-75.487/75.367/44.213/44.333

grdcut pmp5_blmtrealto10000.grd -Gpmp015_blmtrealto10000.grd -R-75.4421^

$-75.4121 / 44.2576 / 44.2876$

grdcut pmp5_blmtrealto10000_1600-400m.grd -Gpmp015_blmtrealto10000_1600-400m.grd

-R-75.4421/-75.4121/44.2576/44.2876

Shift all the values within a surface (stored as tmp.grd ) by their mean (i.e. shift to a zero mean) where \$cutpre is the variable for pmp5, pmp06, pmp015, etc \$outfname=blmtshftto10000 etc.

grdmath tmp.grd $\$$ mean SUB $=\$\{$ cutpre $\}$ \$ $\{$ outfname $\}$. grd

Display a surface as a postscript file with its native (full scale) color gradient and contours

grdimage ../grids/pmp015_blmtshftto10000_1600-400m.grd -R-75.4421/-75.4121/44.2576/44.2876

-C../support/pmp015_blmtshftto10000_1600-400m.cpt

$-\mathrm{JX} 3 \mathrm{id} / 3 \mathrm{id}$

$-\mathrm{K}$

pmp015_blmtshftto10000_1600-400m.ps

grdcontour ../grids/pmp015_blmtshftto10000_1600-400m.grd -R-75.4421/-75.4121/44.2576/44.2876। -C../support/pmp015_blmtshftto-10000_1600-400m_cneg.cpt -JX3id/3id -Wthinnest/255 -A- $-\mathrm{K} \quad-\mathrm{O}>>1$ pmp015_blmtshftto10000_1600-400m.ps

grdcontour ../grids/pmp015_blmtshftto10000_1600-400m.grd -R-75.4421/-75.4121/44.2576/44.2876 -C../support/pmp015_blmtshftto-10000_1600-400m_cpos.cpt -JX3id/3id -Wthinnest/0 -A- $-\mathrm{K} \quad-\mathrm{O} \quad>>$ pmp015_blmtshftto10000_1600-400m.ps

$\begin{array}{llllll}\text { psbasemap } & -B f .003 a .006: .: W e S n & -\mathrm{R}-75.4421 /-75.4121 / 44.2576 / 44.2876 & -J X 3 i d / 3 i d & -O & >>\end{array}$ pmp015_blmtshftto10000_1600-400m.ps 
Display a surface as a postscript file with some relative (to another more inclusive surface residual) color gradient and contour scheme

grdimage ../grids/pmp015_blmtshftto10000_1600-400m.grd -R-75.4421/-75.4121/44.2576/44.2876

-C../support/pmp015_blmtshftto10000_1600-0m.cpt

$-\mathrm{JX} 3 \mathrm{id} / 3 \mathrm{id}$

$-\mathrm{K}$

pmp015_blmtshftto10000_1600-400m.ps

grdcontour ../grids/pmp015_blmtshftto10000_1600-400m.grd -R-75.4421/-75.4121/44.2576/44.2876

-C../support/pmp015_blmtshftto10000_1600-0m_cneg.cpt -JX3id/3id -Wthinnest/255 -A- $\quad-\mathrm{K} \quad-\mathrm{O}>>1$ pmp015_blmtshftto10000_1600-400m.ps

grdcontour ../grids/pmp015_blmtshftto10000_1600-400m.grd -R-75.4421/-75.4121/44.2576/44.2876 -C../support/pmp015_blmtshftto10000_1600-0m_cpos.cpt $\quad$-JX3id/3id $\quad$-Wthinnest/0 $\quad$-A- $\quad$-K $\quad-O \quad>>1$ pmp015_blmtshftto10000_1600-400m.ps

(Possible additional graphical additions based upon support data as in Figures 9d,e and 10a-d

psxy orebody.txt $\quad-R-75.4421 /-75.4121 / 44.2576 / 44.2876-m L-H 10-J X 3 i d / 3 i d \quad-W 2 p \quad-V \quad-K$ -O $\mid>>$ pmp015_blmtshftto10000_1600-400m.ps

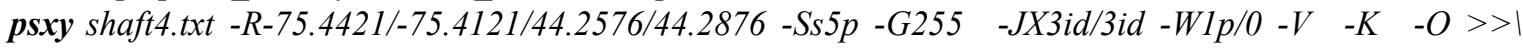
pmp015_blmtshftto10000_1600-400m.ps

psxy blmtSBA001.txt -R-75.4421/-75.4121/44.2576/44.2876 -Sd5p -G0/255/0-Wlp/0 $\quad$-JX3id/3id 1

$-V-K \quad-O>>$ pmp015_blmtshftto10000_1600-400m.ps)

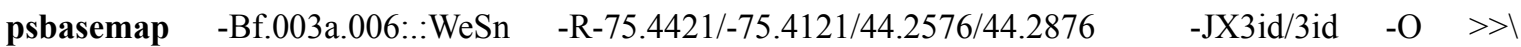
pmp015_blmtshftto10000_1600-400m.ps

\section{Copyrights}

Copyright for this article is retained by the author(s), with first publication rights granted to the journal.

This is an open-access article distributed under the terms and conditions of the Creative Commons Attribution license (http://creativecommons.org/licenses/by/3.0/). 